\title{
A New Methodology of Multicriteria Decision-Making in Supplier Selection Based on Z-Numbers
}

\author{
Bingyi Kang, ${ }^{1}$ Yong $\mathrm{Hu}^{2}{ }^{2}$ Yong Deng, ${ }^{1,2,3}$ and Deyun $\mathrm{Zhou}^{3}$ \\ ${ }^{1}$ School of Computer and Information Sciences, Southwest University, Chongqing 400715, China \\ ${ }^{2}$ Big Data Decision Institute, Jinan University, Tianhe, Guangzhou 510632, China \\ ${ }^{3}$ School of Electronics and Information, Northwestern Polytechnical University, Xian, Shaanxi 710072, China \\ Correspondence should be addressed to Yong Deng; prof.deng@hotmail.com and Deyun Zhou; dyzhou@nwpu.edu.cn
}

Received 14 October 2015; Revised 27 November 2015; Accepted 29 November 2015

Academic Editor: Young Hae Lee

Copyright (C) 2016 Bingyi Kang et al. This is an open access article distributed under the Creative Commons Attribution License, which permits unrestricted use, distribution, and reproduction in any medium, provided the original work is properly cited.

\begin{abstract}
Supplier selection is a significant issue of multicriteria decision-making (MCDM), which has been heavily studied with classical fuzzy methodologies, but the reliability of the knowledge from domain experts is not efficiently taken into consideration. $Z$-number introduced by Zadeh has more power to describe the knowledge of human being with uncertain information considering both restraint and reliability. In this paper, a methodology for supplier selection using $Z$-numbers is proposed considering information transformation. It includes two parts: one solves the issue of how to convert $Z$-number to the classic fuzzy number according to the fuzzy expectation; the other solves the problem of how to get the optimal priority weight for supplier selection with genetic algorithm (GA), which is an efficient and flexible method for calculating the priority weight of the judgement matrix. Finally, an example for supplier selection is used to illustrate the effectiveness the proposed methodology.
\end{abstract}

\section{Introduction}

The selection of suppliers is a significant issue in the business management [1]. As the organization becomes more and more dependent on their suppliers, the direct and indirect consequences of poor decision-making will become more critical. Any deficiency in coordination of the supply chain will lead to excessive delays and poor customer service [2]. An effective methodology for supplier selection is the demand from the current business scenario.

Supplier selection can be modeled as a typical multicriteria decision-making problem. It depends on the broad comparison of suppliers using a common set of traditional criteria and measures. Several methodologies have been proposed for supplier selection. Some of the well-known examples of systematic analysis for domestic supplier selection include a categorical method, weighted point method [3], vendor profile analysis [4], and multiple objective programming [5-7]. Apart from the abovementioned techniques, the related works have been also proposed. Choy and Lee proposed a case-based supplier management tool (CBSMT) using the case-based reasoning $(\mathrm{CBR})$ technique in the areas of intelligent supplier selection and management that will enhance performance as compared to using the traditional approach [8]. Liu et al. demonstrated the application of data envelopment analysis (DEA) in evaluating the overall performances of suppliers in a manufacturing firm [9]. Jiang et al. proposed a model to deal with supplier selection based on fuzzy set in the Dempster-Shafer framework [10]. Cho and Lee proposed a method to deal with supply chain with a seasonal demand process using three levels' information sharing [11]. Mari et al. proposed a network optimization model for a sustainable and resilient supply chain network [12]. Mari et al. also discussed the construction of a resilient supply chain growth algorithm based on a complex network theory for designing a resilient supply chain network [13]. Some other researches related to the issue of supply chain management can also be inspiring, such as [14-16]. Additionally, some models of uncertain information process are proposed to deal with decision-making under uncertain environment $[17,18]$; these methods can be easily expanded to the issue of selection of suppliers. 
The most common and available methodology applied for supplier selection is analytic hierarchy process (AHP). Wang et al. [19] used the advantages of AHP and preemptive goal programming to incorporate both quantitative and qualitative factor in supplier selection problem. Ghodsypour and O'Brien [20] proposed integration of an AHP and linear programming to consider both tangible and intangible factor in choosing the best suppliers and placing optimum order quantities among them. Amid et al. [21] used the AHP to determine the weights of criteria for fuzzy multiobjective supplier selection in a supply chain. Aydin and Kahraman [22] presented an AHP based analytical tool for decision support to establish an effective multicriteria supplier selection process in an air conditioner seller firm under fuzziness. Aydin and Kahraman [22] calculated the weight of each component by fuzzy AHP for balanced and defective supply chain problems. Wang and Yang [23] proposed a fuzzy model for supplier selection in quantity discount environment with method of AHP and fuzzy compromise programming. Yang et al. [24] established a model for vendor selection by integrated fuzzy MCDM techniques with independent and interdependent relationships. Sevkli [25] proposed an approach with AHP weighted fuzzy linear programming model for supplier selection. Chan et al. discussed the fuzzy based analytic hierarchy process (fuzzy AHP) to efficiently tackle both quantitative and qualitative decision factors involved in selection of global supplier in current business scenario and also applied the AHP methodology to select the supplier in the airline industry $[26,27]$. Deng et al. proposed a methodology of DAHP to handle supplier selection based on $D$-number considering the dependence of factors in the system of supplier selection [28]; similarly, $\mathrm{Su}$ et al. discussed the influence of the dependence of factors in the Dempster-Shafer framework in the view of AHP, which can be easily applied in the aspect of supplier selection [29]. Shahgholian et al. [30] proposed a multicriteria group decision-making approach based on fuzzy sets which can solve supplier selection problem that have much vagueness. In Shahgholian et al's method, linguistic variables were used to assess the importance weights of strategic and operational criterion. Some other works from the view of AHP are also demonstrated such as $[31,32]$.

Recently, It is noted that some fuzzy set theories such as $D$-number theory and Grey system theory are applied in the supplier selection. $D$-number theory takes the dependence of information into consideration, which can be useful in the framework with nonexclusive hypotheses [28, 33, 34]. Grey system theory can handle the sensitivity of the system efficiently for the interval number that was used to assess the importance weights of strategic and operational criterion $[35,36]$. However, they cannot deal with the reliability of decision system efficiently.

With reference to the past literatures, it can be observed that the discussion of the reliability of the domain experts for the supplier selection is little and limited. $Z$-number is a new notion proposed by Zadeh in 2011 which has a more power to describe the knowledge of human being [37]. It has a simple structure with constraint and reliability, which can easily represent and handle the reliability of uncertain knowledge. We will take the reliability of pairwise judgement into consideration using $Z$-number. Note that the theory about $Z$-number has not been figured out for its real application, yet the classic fuzzy set theory is relatively mature and has played much important role in the field of approximate reasoning [38, 39], fuzzy control [40, 41], group decision-making $[42,43]$, multiple criteria decision-making [44-46], and so forth.

Hence, how to transform $Z$-number to a classic fuzzy number is a rather significant issue for $Z$-number's application in supplier selection. In this paper, a method of converting $Z$-numbers to classic fuzzy numbers according to fuzzy expectation is introduced. The other problem is how to get the optimal priority weight of the supplier selection; in this paper a new methodology of handling the pairwise judgement with Genetic Algorithm (GA) is proposed, which can get the optimal priority weight. The proposed framework will be introduced in the following sections step by step.

The remainder of the paper is organized as follows: Section 2 discusses some definitions, concepts, and basic theory. In Section 3, the proposed methodology for supplier selection using $Z$-numbers is presented. It contains three parts: the first one is the method of converting $Z$-number to classic fuzzy number according to fuzzy expectation; the other is the methodology for the optimal priority weight with GA and the third part shows the comparison between the proposed method and the classic FAHP for priority weight. Section 4 shows an example in supplier selection to illustrate the proposed approach. Conclusions and future work are made in Section 5.

\section{Preliminaries}

2.1. Fuzzy Sets. In 1965, the notion of fuzzy sets was firstly introduced by Zadeh [47], providing a natural way of dealing with problems in which the source of imprecision is the absence of sharply defined criteria of class membership. The fuzzy set theory can be used in a wide range of domains. A brief introduction of fuzzy sets is given as follows.

Definition 1. A fuzzy set $A$ that is defined on a universe $X$ may be given as follows:

$$
A=\left\{\left\langle x, \mu_{A}(x)\right\rangle \mid x \in X\right\}
$$

where $\mu_{A}: X \rightarrow[0,1]$ is the membership function $A$. The membership value $\mu_{A}(x)$ describes the degree of belongingness of $x \in X$ in $A$.

For a finite set $A=\left\{x_{1}, \ldots, x_{i}, \ldots, x_{n}\right\}$, the fuzzy set $(A, m)$ is often denoted by $\left\{\mu_{A}\left(x_{1}\right) / x_{1}, \ldots, \mu_{A}\left(x_{i}\right) / x_{i}, \ldots\right.$, $\left.\mu_{A}\left(x_{n}\right) / x_{n}\right\}$.

In the real application, the domain experts may give their opinions by fuzzy numbers. For example, in a new product price estimation, one expert may give his opinion as follows: the lowest price is 2 dollars, the most possible price of the product may be 3 dollars, and the highest price of this product will not be in excess of 4 dollars. Hence, we can use a triangular fuzzy number $(2,3,4)$ to represent the expert's 


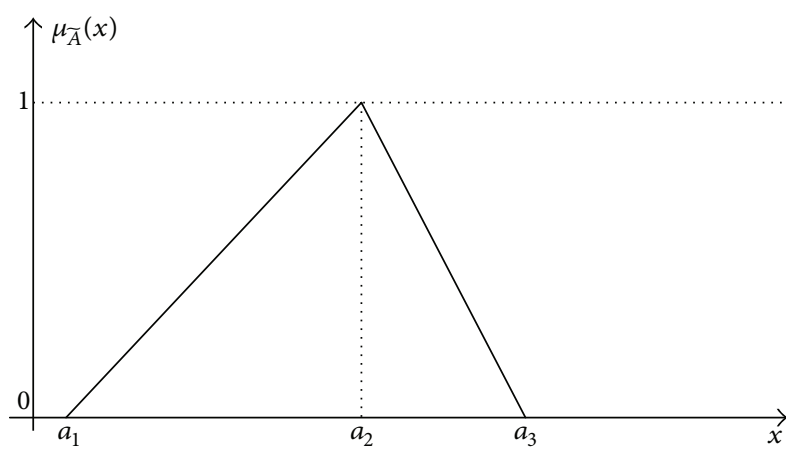

FIgURE 1: A triangular fuzzy number.

opinion. The triangular fuzzy numbers can be defined as follows.

Definition 2. A triangular fuzzy number $\widetilde{A}$ can be defined by a triplet $\left(a_{1}, a_{2}, a_{3}\right)$, where the membership can be determined as follows.

A triangular fuzzy number $\widetilde{A}=\left(a_{1}, a_{2}, a_{3}\right)$ can be shown in Figure 1. Consider

$$
\mu_{\widetilde{A}}(x)= \begin{cases}0, & x \in\left(-\infty, a_{1}\right) \\ \frac{x-a_{1}}{a_{2}-a_{1}}, & x \in\left[a_{1}, a_{2}\right] \\ \frac{c-x}{a_{3}-a_{2}}, & x \in\left[a_{2}, a_{3}\right] \\ 0, & x \in\left(a_{3},+\infty\right) .\end{cases}
$$

Similarly, the trapezoidal fuzzy number can be defined as follows.

Definition 3. A trapezoidal fuzzy number $\widetilde{A}$ can be defined by a triplet $\left(a_{1}, a_{2}, a_{3}, a_{4}\right)$, where the membership can be determined as follows.

A trapezoidal fuzzy number $\widetilde{A}=\left(a_{1}, a_{2}, a_{3}, a_{4}\right)$ can be shown in Figure 2. Consider

$$
\mu_{\widetilde{A}}(x)= \begin{cases}0, & x \in\left(-\infty, a_{1}\right) \\ \frac{1}{\left(a_{2}-a_{1}\right)} x-\frac{a_{1}}{a_{2}-a_{1}}, & x \in\left[a_{1}, a_{2}\right] \\ 1, & x \in\left[a_{2}, a_{3}\right] \\ \frac{-1}{\left(a_{4}-a_{3}\right)} x+\frac{a_{4}}{a_{4}-a_{3}}, & x \in\left[a_{3}, a_{4}\right] \\ 0, & x \in\left(a_{4},+\infty\right) .\end{cases}
$$

Let $X$ be the universe of discourse, which includes five linguistic variables describing the degree of security; $X=$ \{Very Low, Low, Medium, High, Very High\}, assuming that only two adjacent linguistic variables have the overlap of

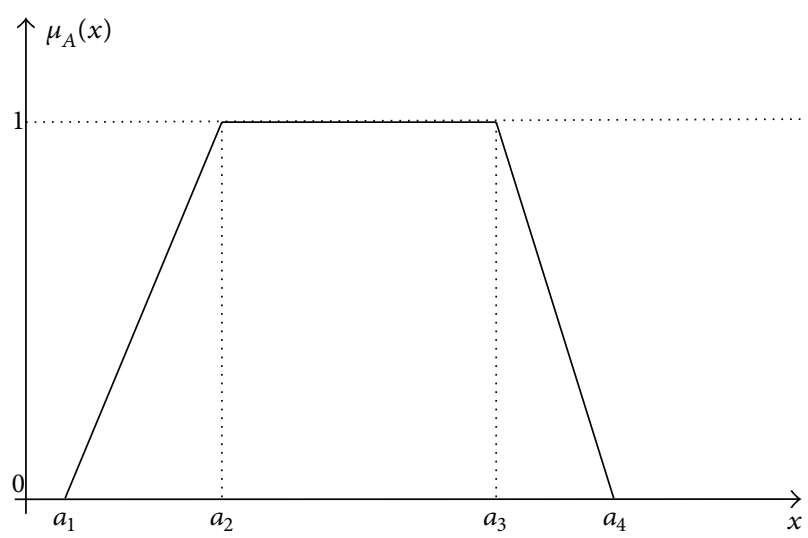

Figure 2: A trapezoidal fuzzy number.

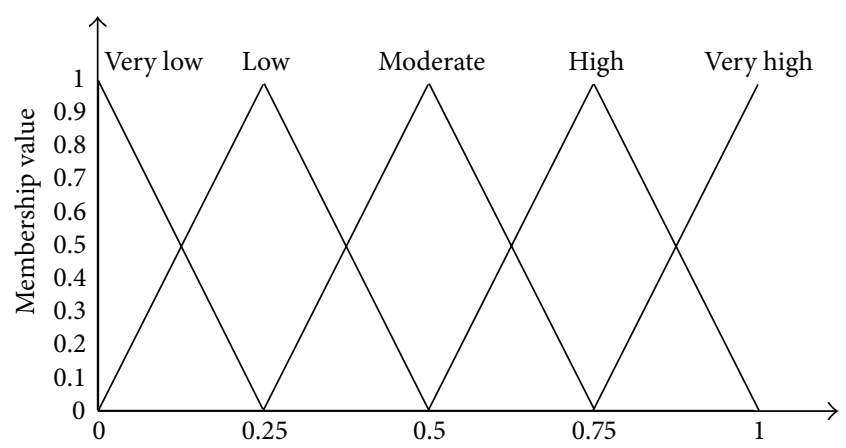

FIGURE 3: Membership function of the triangular fuzzy numbers.

meanings. And let $A$ be a fuzzy set of the universe of discourse $X$ subjectively defined as follows:

$$
\begin{aligned}
& f_{\text {Very Low }}(x)=-4 x+1, \quad 0 \leq x \leq 0.25, \\
& f_{\text {Low }}(x)= \begin{cases}4 x, & 0 \leq x \leq 0.25 \\
-4 x+2, & 0.25 \leq x \leq 0.5,\end{cases} \\
& f_{\text {Medium }}(x)= \begin{cases}4 x-1, & 0.25 \leq x \leq 0.5 \\
-4 x+3, & 0.5 \leq x \leq 0.75,\end{cases} \\
& f_{\text {High }}(x)= \begin{cases}4 x-2, & 0.5 \leq x \leq 0.75 \\
-4 x+4, & 0.75 \leq x \leq 1,\end{cases} \\
& f_{\text {Very High }}(x)=4 x-3, \quad 0.75 \leq x \leq 1,
\end{aligned}
$$

where $f_{\text {Very Low }}, f_{\text {Low }}, f_{\text {Medium }}, f_{\text {High }}$, and $f_{\text {Very High }}$ are the membership function of the fuzzy sets, which are shown in Figure 3.

Definition 4. Let a fuzzy set $A$ be defined on a universe $X$ which may be given as follows:

$$
A=\left\{\left\langle x, \mu_{A}(x)\right\rangle \mid x \in X\right\},
$$

where $\mu_{A}: X \rightarrow[0,1]$ is the membership function $A$. The membership value $\mu_{A}(x)$ describes the degree of 
belongingness of $x \in X$ in $A$. The expectation of a fuzzy number is denoted as follows:

$$
E_{A}(x)=\int_{X} x \mu_{A}(x) d x
$$

which is not the same as the meaning of the Expectation of Probability Space. It is as the Information Strength supporting the fuzzy set $A$.

Example 5. Let fuzzy set $\widetilde{A}$ be defined as $\widetilde{A}=\left\{\left\langle x, \mu_{\widetilde{A}}(x)\right\rangle \mid\right.$ $x \in X\}=(0.72 / 5,0.9 / 6,0.72 / 7)$ :

$$
E_{\widetilde{A}}(x)=0.72 \times 5+0.9 \times 6+0.72 \times 7=14.04 .
$$

Definition 6. The distance of two fuzzy numbers $a$ and $b$ described by $\alpha$-level set is defined as follows:

$$
\begin{aligned}
& d(a, b) \\
& \quad=\int_{0}^{1}\left\{\left[a^{-}(\alpha)-b^{-}(\alpha)\right]^{2}+\left[a^{+}(\alpha)-b^{+}(\alpha)\right]^{2}\right\} d \alpha,
\end{aligned}
$$

where $a$ and $b$ are any two fuzzy numbers and $\left[a^{-}(\alpha), a^{+}(\alpha)\right]$, $\left[b^{-}(\alpha), b^{+}(\alpha)\right]$ is the $\alpha$-level set of two fuzzy numbers $a$ and $b$.

In the real world, uncertainty is a pervasive phenomenon. Much of the information on which decisions are based is uncertain [48-51]. Humans have a remarkable capability to make rational decisions based on information which is uncertain, imprecise, and/or incomplete. Formalization of this capability, at least to some degree, is a challenge that is hard to meet [52, 53]. Zadeh proposed a notion, namely, $Z$ number, which is an ordered pair of fuzzy numbers $(A, B)$. The first component, $A$, plays the role of a fuzzy restriction. And the second component, $B$, is a reliability of the first component [37]. The definition of $Z$-number is shown below.

2.2. Z-Numbers. A new concept, $Z$-numbers, is proposed by Zadeh to model uncertain information [37]. A $Z$-number can be defined as an ordered pair of fuzzy numbers as follows.

Definition 7. A $Z$-number is an ordered pair of fuzzy numbers denoted as $Z=(\widetilde{A}, \widetilde{R})$. The first component $\widetilde{A}$, a restriction on the values, is a real-valued uncertain variable $X$. The second component $\widetilde{R}$ is a measure of reliability for the first component.

Zadeh [37] points out that $R$ is a restriction on the probability measure of $A$ rather than on the probability of $A$. Conversely, if $R$ is a restriction on the probability of $A$ rather than on the probability measure of $A$, then $(A, R)$ is not a $Z$ number. It means that $R$ measures the sureness, confidence, and reliability of measurement of restriction of $R$.

$Z$-numbers can be used to model uncertain information in the real world. For example, in risk analysis, the loss of severity of the fifth component is very low, with a confidence of very likely, which can be written as a $Z$-number as follows: $Z=$ (very low, very likely). For simplicity, $\widetilde{A}$ and $\widetilde{B}$ are assumed as triangular fuzzy numbers as defined earlier in (4) and Figure 3.
Then the notion of AHP will be introduced as follows. The first step of AHP is to establish a hierarchical structure of the problem. In each hierarchical level, a nominal scale is used to construct pairwise comparison judgement matrix.

Definition 8. Assuming $\left(E_{1}, \ldots, E_{i}, \ldots, E_{n}\right)$ are $n$ decision elements, the pairwise comparison judgement matrix is denoted as $M_{n \times n}=\left[m_{i j}\right]$, which satisfies

$$
m_{i j}=\frac{1}{m_{j i}},
$$

where each element $m_{i j}$ represents the judgement concerning the relative importance of decision element $E_{i}$ over $E_{j}$.

Definition 9. Eigenvector of $n \times n$ pairwise comparison judgement matrix can be denoted as $\vec{w}=\left(w_{1}, \ldots, w_{i}, \ldots, w_{n}\right)^{T}$, which is calculated as follows:

$$
A \vec{w}=\lambda_{\max } \vec{w}, \quad \lambda_{\max } \geq n,
$$

where $\lambda_{\max }$ is the maximum eigenvalue in the eigenvector $\vec{w}$ of matrix $M_{n \times n}$.

Definition 10. Consistency index (CI) [54] is used to measure the inconsistency within each pairwise comparison judgement matrix, which is formulated as follows:

$$
\mathrm{CI}=\frac{\lambda_{\max }-n}{n-1} .
$$

Accordingly, the consistency ratio (CR) can be calculated by using the following equation:

$$
\mathrm{CR}=\frac{\mathrm{CI}}{\mathrm{RI}},
$$

where RI is the random consistency index. The value of RI is related to the dimension of the matrix, which is listed in Table 2.

If the result of CR is less than 0.1, the consistency of the pairwise comparison matrix $M$ is acceptable. Moreover, the eigenvector of pairwise comparison judgement matrix can be normalized as final weights of decision elements. Otherwise, the consistency is not passed and the elements in the matrix should be revised.

2.3. FAHP. In this section, we briefly introduce a typical FAHP method. For detailed information, please refer to $[2$, $55,56]$.

In the first step, triangular fuzzy numbers are used for pairwise comparisons. Then, by using extent analysis method, the synthetic extent value $S_{i}$ of the pairwise comparison is introduced and by applying the principle of the comparison of fuzzy numbers, the weight vectors with respect to each element under a certain criterion are calculated. The details of the methodology are presented in the following steps.

Let $X=\left\{x_{1}, x_{2}, \ldots, x_{n}\right\}$ be an object set and let $U=$ $\left\{u_{1}, u_{2}, \ldots, u_{m}\right\}$ be a goal set. According to the method of Chang's extent analysis, each object is taken and an extent 


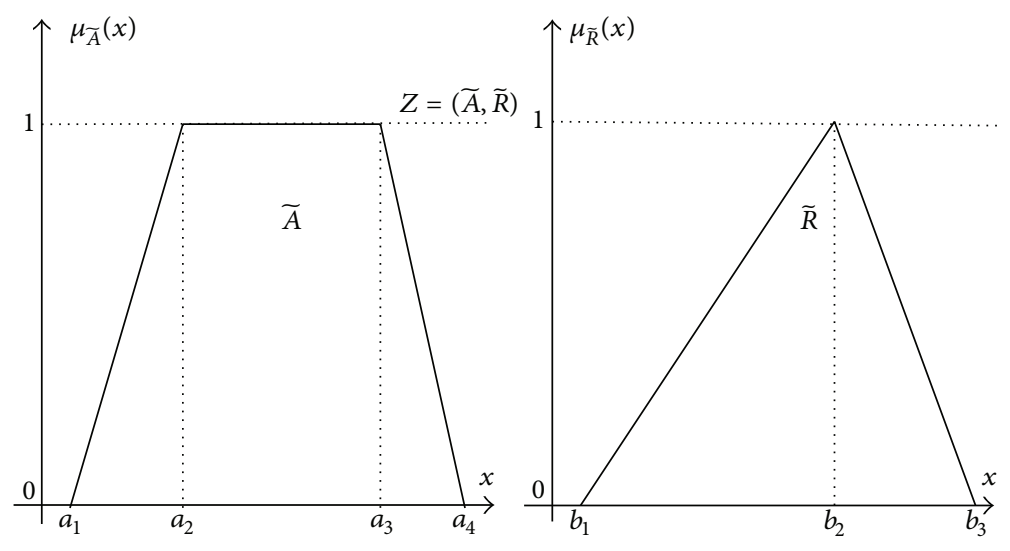

FIgure 4: A simple $Z$-number.

analysis for each goal, $g_{i}$, is performed. Therefore, $m$ extent analysis values for each object can be obtained, with the following signs: $M_{g_{i}}^{1}, M_{g_{i}}^{2}, \ldots, M_{g_{i}}^{m}, i=1,2, \ldots, n$, where all $M_{g_{i}}^{j}(j=1,2, \ldots, m)$ are TFNs.

Step 1. The value of fuzzy synthetic extent with respect to the $i$ th object is defined as

$$
S_{i}=\sum_{j=1}^{m} M_{g_{i}}^{j} \otimes\left\{\sum_{i=1}^{n} \sum_{j=1}^{m} M_{g_{i}}^{j}\right\}^{-1}
$$

In order to obtain $\sum_{j=1}^{m} M_{g_{i}}^{j}$, perform the fuzzy addition operation of $m$ extent analysis values for a particular matrix such that

$$
\sum_{j=1}^{m} M_{g_{i}}^{j}=\left(\sum_{j=1}^{m} l_{j}, \sum_{j=1}^{m} m_{j}, \sum_{j=1}^{m} u_{j}\right) .
$$

To obtain $\left\{\sum_{i=1}^{n} \sum_{j=1}^{m} M_{g_{i}}^{j}\right\}^{-1}$, perform the fuzzy addition operation of $M_{g_{i}}^{j}(j=1,2, \ldots, m)$ values such that

$$
\sum_{i=1}^{n} \sum_{j=1}^{m} M_{g_{i}}^{j}=\left(\sum_{i=1}^{n} l_{i}, \sum_{i=1}^{n} m_{i}, \sum_{i=1}^{n} u_{i}\right)
$$

and then compute the inverse of the vector.

Step 2. The degree of possibility of $M_{2}=\left(l_{2}, m_{2}, u_{2}\right) \geq M_{1}=$ $\left(l_{1}, m_{1}, u_{1}\right)$ is expressed as follows:

$$
\begin{aligned}
& V\left(M_{2} \geq M_{1}\right)=\operatorname{hgt}\left(M_{1} \geq M_{2}\right) \\
& \quad= \begin{cases}1, & \text { if } m_{2} \geq m_{1} \\
\frac{\left(l_{1}-u_{2}\right)}{\left(\left(m_{2}-u_{2}\right)-\left(m_{1}-l_{1}\right)\right)} & \text { otherwise } \\
0, & \text { if } l_{1} \geq u_{2} .\end{cases}
\end{aligned}
$$

To compare $M_{1}$ and $M_{2}$, both $V\left(M_{2} \geq M_{1}\right)$ and $V\left(M_{1} \geq M_{2}\right)$ are required.
Step 3. The degree of possibility for a convex fuzzy number to be greater than $k$ convex fuzzy numbers $M_{i}(i=1,2, \ldots, k)$ can be defined as

$$
\begin{aligned}
V & \left(M \geq M_{1}, M_{2}, \ldots, M_{k}\right) \\
& =V\left[\left(M \geq M_{1}\right),\left(M \geq M_{2}\right), \ldots,\left(M \geq M_{k}\right)\right] \\
& =\min V\left(M \geq M_{i}\right), \quad i=1,2, \ldots, k .
\end{aligned}
$$

Let $d^{\prime}\left(A_{i}\right)=\min V\left(S_{i} \geq S_{k}\right)$, for $k=1,2, \ldots, n ; k \neq i$. Then the weight vector is given by

$$
W^{\prime}=\left(d^{\prime}\left(A_{1}\right), d^{\prime}\left(A_{2}\right), \ldots, d^{\prime}\left(A_{n}\right)\right)^{T} .
$$

Step 4. The weight vector obtained in Step 3 is normalized to get the normalized weights.

In the following part, the methodology for supplier selection using $Z$-number is proposed, which includes three parts: the first is how to convert $Z$-number to a classic fuzzy number; the second is how to get the optimal priority weight; the process is shown in Figure 7. The first part corresponds to (1) shown in Figure 7 and the second part corresponds to (2), (3), and (4) in Figure 7; the third one is a comparison between the proposed method for the optimal priority weight and the classic fuzzy AHP.

\section{The Proposed Methodology for Supplier Selection Using $Z$-Numbers}

In the following subsection, a method of changing a $Z$ number to a classic fuzzy number is used [57] according to the fuzzy expectation. Then the pairwise reciprocal judging matrices are converted to classic reciprocal judging matrices.

3.1. The Method of Changing a Z-Number to a Classic Fuzzy Number. Assume a $Z$-number $Z=(\widetilde{A}, \widetilde{R})$, which is shown in Figure 4. The left is the part of restriction, and the right is the part of reliability. Let $\widetilde{A}=\left\{\left\langle x, u_{\widetilde{A}}(x)\right\rangle \mid x \in X\right\}$ and $\widetilde{R}=\left\{\left\langle x, u_{\widetilde{R}}(x)\right\rangle \mid x \in X\right\}$. Assume $u_{\widetilde{A}}(x)$ is a trapezoidal membership function and $u_{\widetilde{R}}(x)$ is a triangular membership function. 


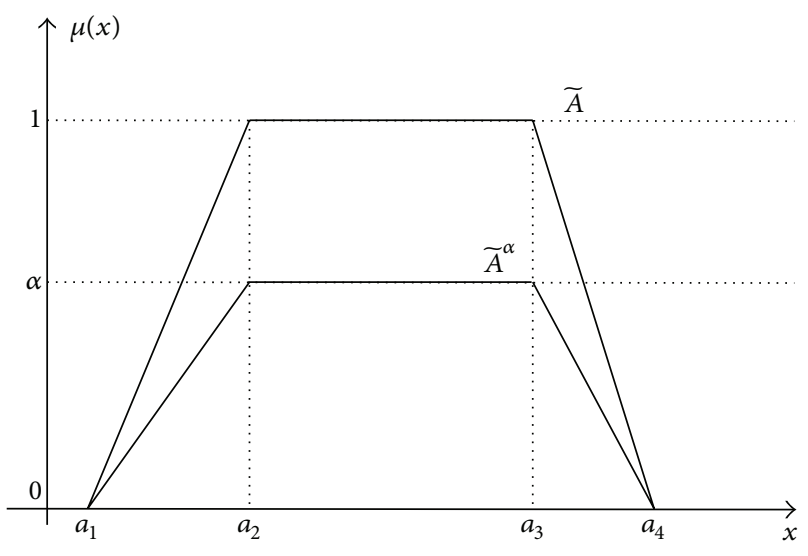

FIGURE 5: $Z$-number after multiplying the confidence.

3.1.1. Convert the Second Part (Reliability) into a Crisp Number with Centroid Method. Consider

$$
\alpha=\frac{\int x \mu_{\widetilde{R}}(x) d x}{\int \mu_{\widetilde{R}}(x) d x},
$$

where $\int$ denotes an algebraic integration.

3.1.2. Add the Weight of the Second Part (Reliability) to the First Part (Restriction). The weighted $Z$-number can be denoted as $\widetilde{Z}^{\alpha}=\left\{\left\langle x, \mu_{\widetilde{A}^{\alpha}}(x)\right\rangle \mid \mu_{\widetilde{A}^{\alpha}}(x)=\alpha \mu_{\widetilde{A}}(x), x \in X\right\}$.

Theorem 11. Consider

$$
\begin{aligned}
& \mu_{\widetilde{A}^{\alpha}}(x)=\alpha \mu_{\widetilde{A}}(x), \quad x \in X, \\
& E_{\widetilde{A}^{\alpha}}(x)=\alpha E_{\widetilde{A}}(x), \quad x \in X .
\end{aligned}
$$

Proof. Consider

$$
\begin{aligned}
E_{\widetilde{A}^{\alpha}}(x) & =\int_{X} x \mu_{\widetilde{A}^{\alpha}}(x) d x=\int_{X} \alpha x \mu_{\widetilde{A}}(x) d x \\
& =\alpha \int_{X} x \mu_{\widetilde{A}}(x) d x=\alpha E_{\widetilde{A}}(x)
\end{aligned}
$$

which can be shown in Figure 5.

3.1.3. Convert the Irregular Fuzzy Number (Weighted Restriction) to Regular Fuzzy Number. The converted regular fuzzy number is $\mu_{\widetilde{Z}^{\prime}}(x)=\mu_{\widetilde{A}}(x / \sqrt{\alpha}), x \in \sqrt{\alpha} X$.

Theorem 12. Consider

$$
\begin{aligned}
& \mu_{\widetilde{Z}^{\prime}}(x)=\mu_{\widetilde{A}}\left(\frac{x}{\sqrt{\alpha}}\right), \quad x \in \sqrt{\alpha} X, \\
& E_{\widetilde{Z}^{\prime}}(x)=\alpha E_{\widetilde{A}}(x), \quad x \in \sqrt{\alpha} X .
\end{aligned}
$$

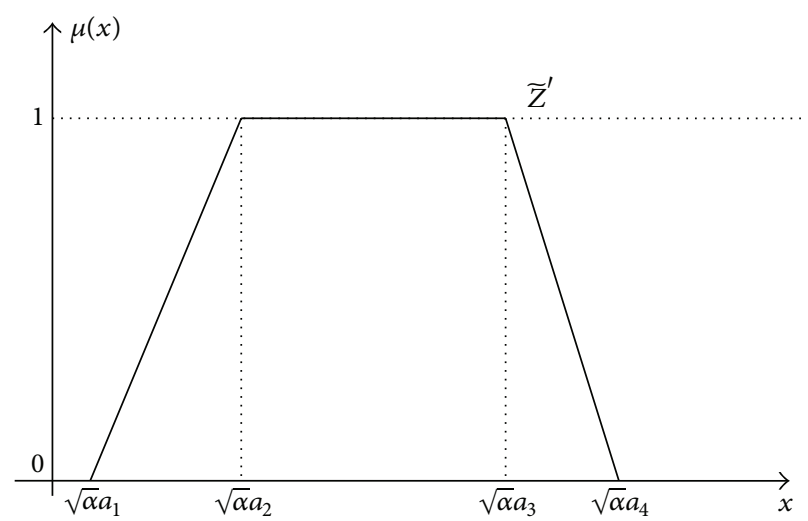

FIgURE 6: The regular fuzzy number transformed from $Z$-number.

Proof. Consider

$$
\begin{aligned}
& E_{\widetilde{Z}^{\prime}}(x)=\int_{\sqrt{\alpha} X} x \mu_{\widetilde{Z}^{\prime}}(x) d x=\int_{\sqrt{\alpha} X} x \mu_{\widetilde{A}}\left(\frac{x}{\sqrt{\alpha}}\right) d x, \\
& \stackrel{x=\sqrt{\alpha} t}{=} \int_{X}(\sqrt{\alpha} t) \mu_{\widetilde{A}}(t) d(\sqrt{\alpha} t)=\alpha \int_{X} t \mu_{\widetilde{A}}(t) d t \\
& =\alpha E_{\widetilde{A}}(x)
\end{aligned}
$$

which can be shown in Figure 6 .

Theorem 13. Consider

$$
E_{\widetilde{Z}^{\prime}}(x)=E_{\widetilde{A}^{\alpha}}(x) .
$$

Proof. From (21) and (24),

$$
\begin{aligned}
& E_{\widetilde{A}^{\alpha}}(x)=\alpha E_{\widetilde{A}}(x), \\
& E_{\widetilde{Z}^{\prime}}(x)=\alpha E_{\widetilde{A}}(x), \\
& E_{\widetilde{Z}^{\prime}}(x)=E_{\widetilde{A}^{\alpha}}(x) .
\end{aligned}
$$

Here a simple numerical example is used to illustrate the proposed method of converting a $Z$-number to a classical fuzzy number.

Example 14. Assume that an expert gives his opinion as follows:

$$
\widetilde{A}=(0.7,0.8,0.9,1 ; 1)
$$

and his reliability, confidence, sureness, strength of belief, and so forth are

$$
\widetilde{R}=(0.8,0.9,1 ; 1) \text {. }
$$

Hence the expert's knowledge can be expressed with $Z$ number as

$$
\widetilde{Z}=(\widetilde{A}, \widetilde{R})=[(0.7,0.8,0.9,1 ; 1),(0.8,0.9,1 ; 1)]
$$



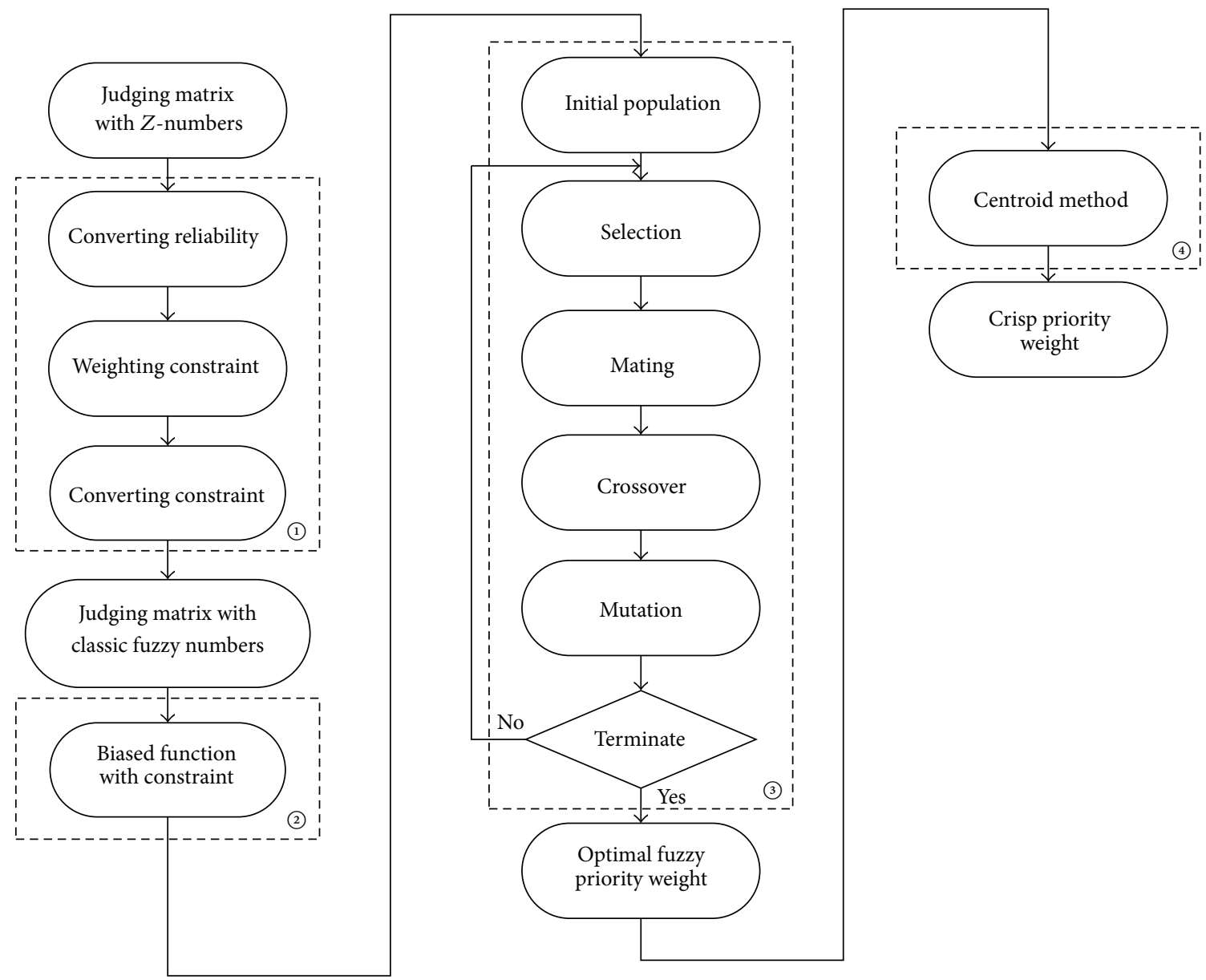

Figure 7: Methodology for the weight of the pairwise reciprocal judging matrix with $Z$-numbers in supplier selection. (1) A method of converting $Z$-number to classic fuzzy number; (2) an objective function according to the min-bias to the consistent weight; (3) the genetic algorithm is applied to solve the optimal fuzzy weight; (4) a centroid method is used to convert the fuzzy weight to crisp priority weight.

At first, we should convert expert's reliability into crisp number according to (19):

$$
\alpha=\frac{\int x \mu_{\widetilde{R}}(x) d x}{\int \mu_{\widetilde{R}}(x) d x}=0.9 .
$$

Second, add the weight of reliability $\widetilde{R}$ to the constraint $\widetilde{A}$ :

$$
\bar{Z}^{\alpha}=(0.7,0.8,0.9,1 ; 0.9) \text {. }
$$

Third, convert the weighted $Z$-number to regular fuzzy number according to the proposed approach:

$$
\begin{aligned}
\widetilde{Z}^{\prime} & \\
& =(\sqrt{0.9} \times 0.7, \sqrt{0.9} \times 0.8, \sqrt{0.9} \times 0.9, \sqrt{0.9} \times 1 ; 1) \\
& =(0.95 \times 0.7,0.95 \times 0.8,0.95 \times 0.9,0.95 \times 1 ; 1) \\
& =(0.66,0.76,0.85,0.95 ; 1) .
\end{aligned}
$$

From the proof above, it can be concluded that the fuzzy expectation of $\widetilde{Z}^{\prime}$ and the fuzzy expectation of $\widetilde{Z}^{\alpha}$ are equal.
In the following subsection, the methodology for the optimal priority weight is proposed. At first, a reciprocal judging matrix using $Z$-numbers is shown. Then the method of converting $Z$-number to classic fuzzy number shown as the subsection above is applied. Note that the inconsistency is a common phenomenon in the decision-making; the genetic algorithm is used to figure out the optimal fuzzy priority weights. An illustration will be used to prove its advantage with the most popular method proposed by Chang [55]. At last, the centroid method is used to get the crisp priority weight. The procedure can be shown in Figure 7.

3.2. The Methodology for the Optimal Priority Weight. In most situations, nonconsensus is a common phenomenon in the group decision-making. Although the fuzzy set has been applied to soften the conflicts among the different opinions from experts, how to get the optimal priority weight is a critical problem and open issue. In this part, a biased function is defined to establish the objective function. Then the problem is converted to solve the optimal issue under some constraint. In the following, the methodology of searching the optimal priority weight based on GA is proposed. 
A reciprocal judging matrix $A=\left(a_{i j}\right)_{n \times n}$ is consistent if and only if $a_{i j} \cdot w_{j}=w_{i}(i, j \in N)$, where $w_{i}=$ $\left(w_{i l}, w_{i m}, w_{i u}\right)(i \in N)$ is the eigenvector of the matrix $A=\left(a_{i j}\right)_{n \times n}$. However, the consistency of the reciprocal judging matrix $A=\left(a_{i j}\right)_{n \times n}$ is always not satisfied due to the complexity of the real application, and the equation $a_{i j} \cdot w_{j}=$ $w_{i}(i, j \in N)$ is not satisfied.

Hence, when the reciprocal judging matrix $A=\left(a_{i j}\right)_{n \times n}$ with triangular fuzzy number is inconsistent, the biased function is defined as follows:

$$
\begin{aligned}
& f_{i j}^{-}(\alpha)=a_{i j}^{-}(\alpha) w_{j}^{-}(\alpha)-w_{i}^{-}(\alpha), \\
& f_{i j}^{+}(\alpha)=a_{i j}^{+}(\alpha) w_{j}^{+}(\alpha)-w_{i}^{+}(\alpha),
\end{aligned}
$$

where $i, j \in N,\left[a_{i j}^{-}(\alpha), a_{i j}^{+}(\alpha)\right]$ is the $\alpha$-set cut of fuzzy number $a_{i j}$, and $\left[w_{i}^{-}(\alpha), w_{i}^{+}(\alpha)\right]$ is the $\alpha$-set cut of fuzzy number $w_{i}$, and $\left[w_{j}^{-}(\alpha), w_{j}^{+}(\alpha)\right]$ is the $\alpha$-set cut of fuzzy number $w_{j}, 0 \leq$ $\alpha \leq 1$.

From (8), the biased function can be denoted as follows:

$$
f_{i j}^{2}=\int_{0}^{1}\left[f_{i j}^{-}(\alpha)^{2}+f_{i j}^{+}(\alpha)^{2}\right] d \alpha, \quad i, j \in N
$$

Obviously, the solved priority weight should make the value of (35) to get the minimum. Hence the objective function for the reciprocal judging matrix using triangular fuzzy numbers can be denoted as follows:

$$
\begin{array}{ll}
\min & F=\sum_{i=1}^{n} \sum_{j=1}^{n} f_{i j}^{2} \\
\text { s.t. } & 0 \leq w_{i l} \leq w_{i m} \leq w_{i u} \leq 1 \\
& \sum_{i=1}^{n} w_{i l} \leq 1 \\
& \sum_{i=1}^{n} w_{i m}=1 \\
& \sum_{i=1}^{n} w_{i u} \geq 1 \\
& i \in N .
\end{array}
$$

The above function (36) equals the following equation denoted as

$$
\begin{array}{ll}
\min \quad & F=\sum_{i=1}^{n} \sum_{j=1}^{n} \int_{0}^{1}\left[\left[a_{i j}^{-}(\alpha) w_{j}^{-}(\alpha)-w_{i}^{-}(\alpha)\right]^{2}+\left[a_{i j}^{+}(\alpha) w_{j}^{+}(\alpha)-w_{i}^{+}(\alpha)\right]^{2}\right] d \alpha \\
\text { s.t. } & 0 \leq w_{i l} \leq w_{i m} \leq w_{i u} \leq 1 \\
& \sum_{i=1}^{n} w_{i l} \leq 1 \\
& \sum_{i=1}^{n} w_{i m}=1 \\
& \sum_{i=1}^{n} w_{i u} \geq 1 \\
& i \in N .
\end{array}
$$

Such nonlinear programming models can be easily implemented by using existing optimization packages such as LINGO software package or MATLAB optimization tool box. Note that genetic algorithm is an available tool to solve the optimal issue, which has an excellent power to search the global optimal solution with complex constraints [58-60]; it is applied to figure out the optimal fuzzy priority weight $w_{i}=\left(w_{i l}, w_{i m}, w_{i u}\right)(i \in N)$. In this paper, the parameters of experimental GA are some default values (population size: 20; scaling function: rank; selection function: stochastic uniform; elite count: 2 ; crossover fraction: 0.8 ; mutation function: constraint dependent; crossover function: scattered; migration-direction: forward; migration-fraction: 0.2 ; migration-interval: 20; constraint parameter-initial penalty: 10; constraint parameter-penalty factor: 100; hybrid function: none; stopping criteria: 100 , Inf, - Inf, 50 , Inf, $\left.1 e^{-6}, 1 e^{-6}\right)$. Then the centroid method is applied to convert the optimal fuzzy priority weight to crisp weight.

The following example is used to illustrate the proposed method for the priority weight of the judging matrix using $Z$-numbers.

Example 15. This example is used to calculate the weight of three different criteria through fuzzy evaluation matrix; the fuzzy evaluation of the criteria is constructed by the pairwise comparison of the different criterion relevant to the overall object using $Z$-numbers, which is shown in Table 2 . The linguistic variable is applied to represent the experts' opinion, which is defined like Figure 3.

Firstly, we should convert the linguistic variables to numerical $Z$-numbers denoted by Table 3 . 

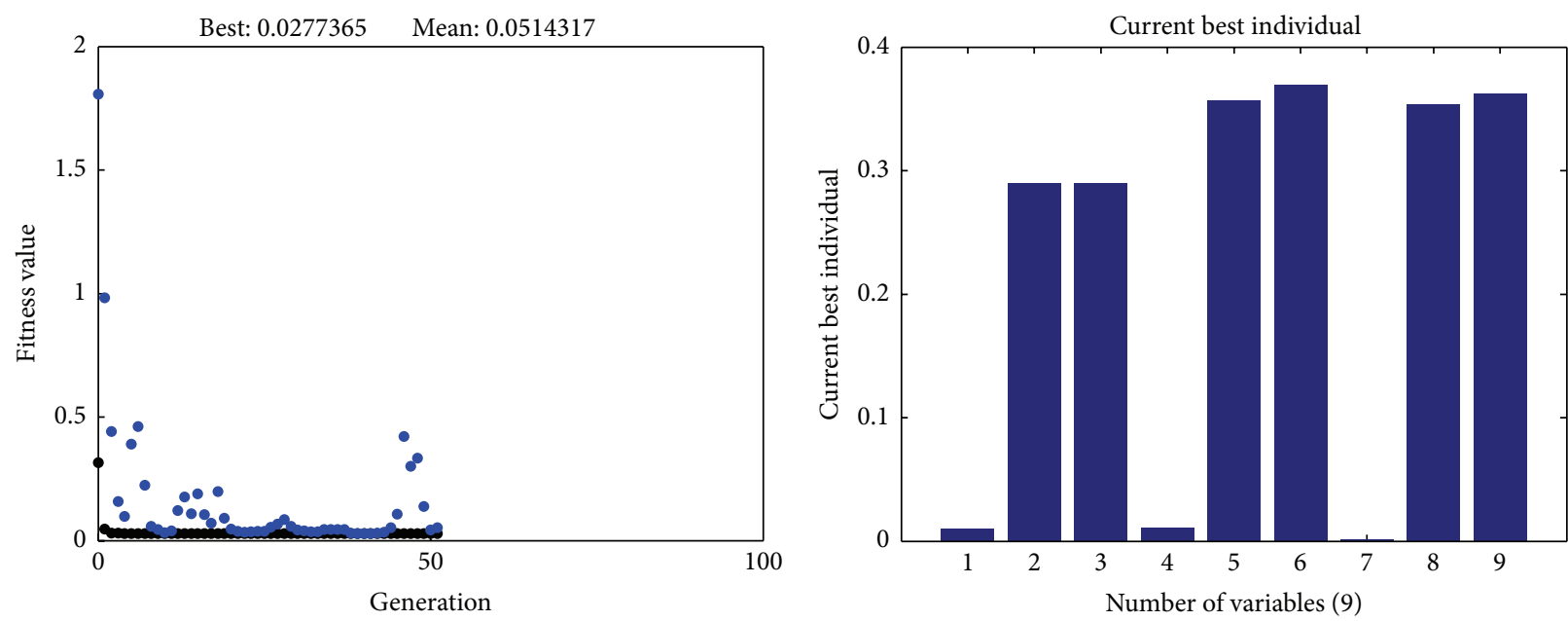

- Best fitness

- Mean fitness
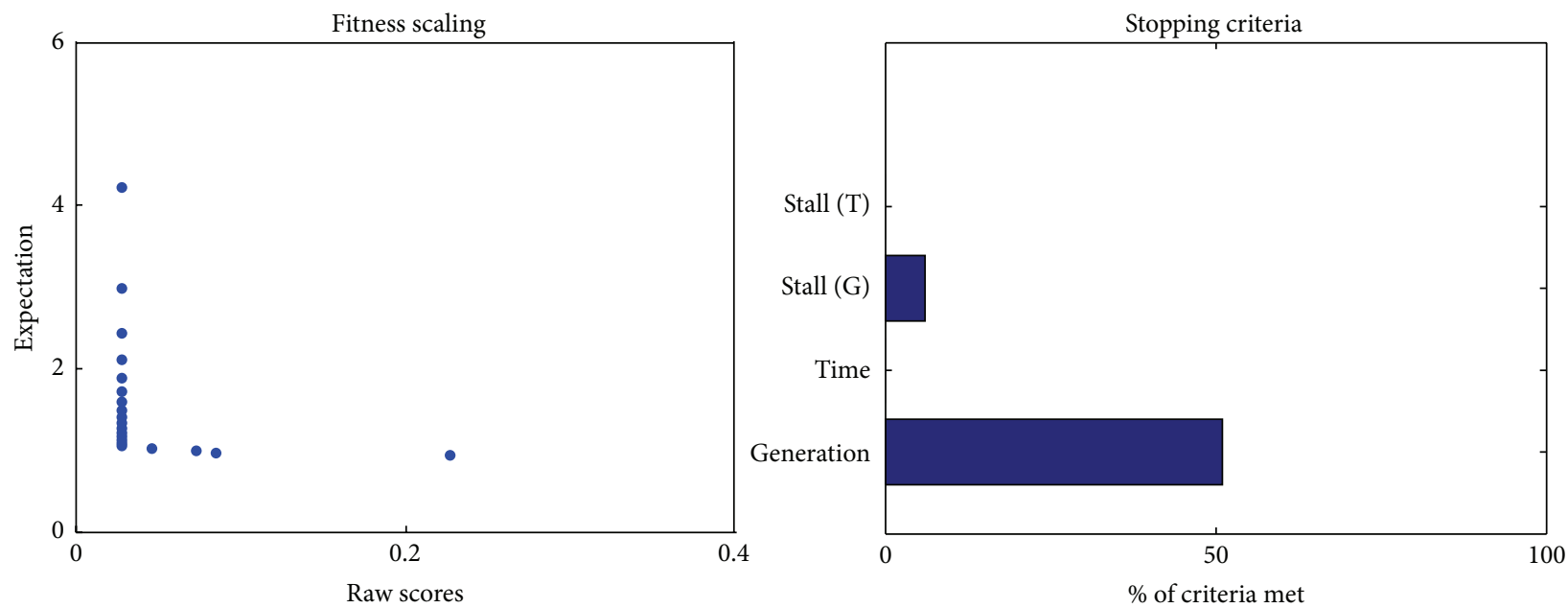

FIGURE 8: Optimal fuzzy priority weight (upper right) with genetic algorithm. Parameters of GA are as follows: population size: 20; scaling function: rank; selection function: stochastic uniform; elite count: 2; crossover fraction: 0.8; mutation function: constraint dependent; crossover function: scattered; migration-direction: forward; migration-fraction: 0.2 ; migration-interval: 20; constraint parameter-initial penalty: 10; constraint parameter-penalty factor: 100; hybrid function: none; stopping criteria: $100, \operatorname{Inf},-\operatorname{Inf}, 50, \operatorname{Inf}, 1 e^{-6}, 1 e^{-6}$.

Secondly, according to the proposed method of converting $Z$-number to regular fuzzy number, we can get the regular triangular fuzzy number matrix shown in Table 4.

Suppose that the fuzzy variable is $w_{1}=\left(w_{1 l}, w_{1 m}, w_{1 u}\right)$, $w_{2}=\left(w_{2 l}, w_{2 m}, w_{2 u}\right)$, and $w_{3}=\left(w_{3 l}, w_{3 m}, w_{3 u}\right)$; then the objective function according to (36) can be established. After the procedure of selection, mating, crossover, and mutation of genetic algorithm, the optimal fuzzy weight can be figured out as

$$
\widetilde{W}=\left(w_{1}, w_{2}, w_{3}\right)^{T}
$$

where $w_{1}=\left(w_{1 l}, w_{1 m}, w_{1 u}\right)=(0.01,0.29,0.29), w_{2}=$ $\left(w_{2 l}, w_{2 m}, w_{2 u}\right)=(0.01,0.36,0.37), w_{3}=\left(w_{3 l}, w_{3 m}, w_{3 u}\right)=$ $(0.01,0.35,0.36)$, and the minimum of the objective function is 0.0277 . The detailed result is shown in Figure 8 .
According to the centroid method, the fuzzy priority can be defuzzified as

$$
W^{\prime}=\left(w_{1}, w_{2}, w_{3}\right)^{T}=(0.20,0.25,0.24) .
$$

The normalized priority weight is

$$
W=\left(w_{1}, w_{2}, w_{3}\right)^{T}=(0.29,0.36,0.35)^{T} .
$$

3.3. The Methodology for the Optimal Weight Comparing with the Classic FAHP. Inconsistency is a critical problem that should be taken into consideration in the process of decision-making. Although the extent analysis method on fuzzy AHP proposed by Chang [55] has been applied to soften the conflicts from different experts/commanders, it is still lack of capability to handle this issue. Sometimes, Chang's method gets an unreasonable result in spite of the fact that the decision-matrix is consistent according to the calculation 
TABLE 1: The value of RI (random consistency index).

\begin{tabular}{lcccccccccc}
\hline Dimension & 1 & 2 & 3 & 4 & 5 & 6 & 7 & 8 & 9 & 10 \\
\hline RI & 0 & 0 & 0.52 & 0.89 & 1.12 & 1.26 & 1.36 & 1.41 & 1.46 & 1.49 \\
\hline
\end{tabular}

TABLE 2: Linguistic evaluation of criteria.

\begin{tabular}{lccc}
\hline & $C_{1}$ & $C_{2}$ & $C_{3}$ \\
\hline$C_{1}$ & - & $(\mathrm{H}, \mathrm{VH})$ & $(\mathrm{VH}, \mathrm{H})$ \\
$C_{2}$ & $\left(\mathrm{H}^{-1}, \mathrm{VH}\right)$ & - & $(\mathrm{VH}, \mathrm{VH})$ \\
$C_{3}$ & $\left(\mathrm{VH}^{-1}, \mathrm{H}\right)$ & $\left(\mathrm{VH}^{-1}, \mathrm{VH}\right)$ & - \\
\hline
\end{tabular}

method of consistency index and consistency ratio presented by Kwong [61]. Kwong's method has been used to check the consistency of pairwise judgement of each comparison matrix in the application of global supplier development [2].

Now, a designed example is used to denote the shortcoming of the extent analysis method on fuzzy AHP and to illustrate the efficiency and advantage of our proposed method.

Suppose that a designed comparison matrix with three criteria $\left(C_{1}, C_{2}, C_{3}\right)$ is constructed according to the pairwise judgement, which is shown in Table 5.

Then, Kwong's method will be also applied to check the consistency of comparison matrix (Table 5). The detailed steps are shown as follows.

First, a triangular fuzzy number, denoted as $M=(l, m, u)$, can be defuzzified to a crisp number as follows:

$$
M_{-} \text {crisp }=\frac{(4 m+l+u)}{6} .
$$

Hence, the crisp comparison matrix can be calculated according to formula (41); the crisp comparison matrix is shown in Table 6.

Then, the consistency index (CI) and the consistency ratio (CR) for a comparison matrix can be computed with the use of the following formulas:

$$
\begin{gathered}
\mathrm{CI}=\frac{\left(\lambda_{\max }-n\right)}{(n-1)}=\frac{(3.06-3)}{(3-1)}=0.03, \\
\mathrm{CR}=\left(\frac{\mathrm{CI}}{\mathrm{RI}(n)}\right) 100 \%=\frac{0.03}{0.52}=0.06<0.1,
\end{gathered}
$$

where $\lambda_{\max }$ is the largest eigenvalue of the comparison matrix, $n$ is the dimension of the matrix, and $\mathrm{RI}(n)$ is a random index, which depends on $n$, as shown in Table 1 .

As seen in formulas (42), the consistency ratio is less than 0.1 , and the pairwise judgement of comparison matrix is consistent.

Now, we will use the extent analysis method on fuzzy AHP proposed by Chang [55] to calculate the weight of the comparison matrix (see Table 5).

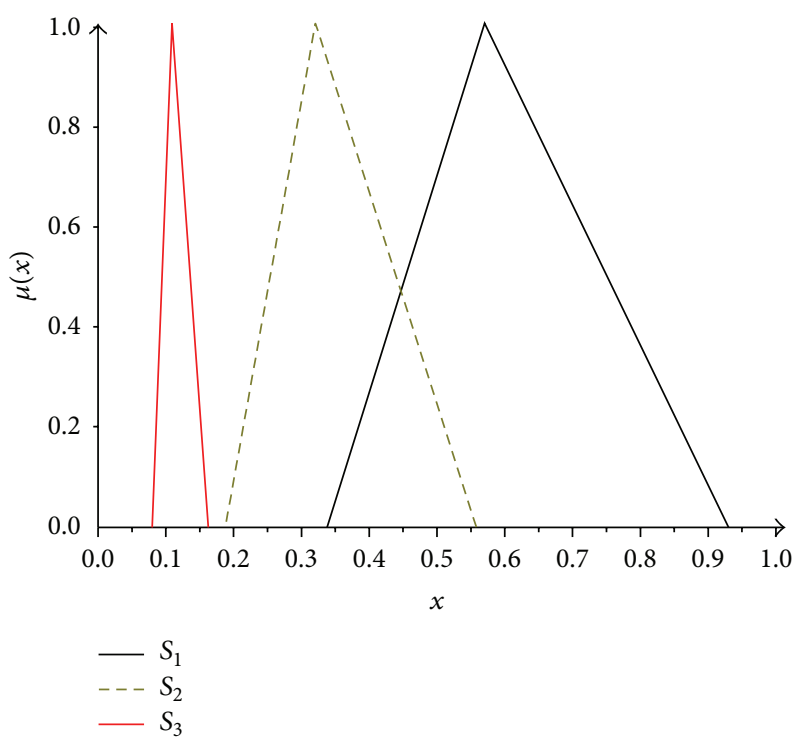

FIGURE 9: Relation of the fuzzy synthetic extent $S_{1}, S_{2}, S_{3}$.

First Step. By applying formula (13), we have

$$
\begin{aligned}
S_{1} & =(6.0,8.0,10) \otimes\left(\frac{1}{17.75}, \frac{1}{14.03}, \frac{1}{10.75}\right) \\
& =(0.34,0.57,0.93), \\
S_{2} & =(3.3,4.5,6.0) \otimes\left(\frac{1}{17.75}, \frac{1}{14.03}, \frac{1}{10.75}\right) \\
& =(0.19,0.32,0.56), \\
S_{3} & =(1.4,1.5,1.75) \otimes\left(\frac{1}{17.75}, \frac{1}{14.03}, \frac{1}{10.75}\right) \\
& =(0.08,0.11,0.16) .
\end{aligned}
$$

The relation among $S_{1}, S_{2}$, and $S_{3}$ is shown in Figure 9. Using formulas (16),

$$
\begin{aligned}
V\left(S_{1} \geq S_{2}\right) & =1 \\
V\left(S_{1} \geq S_{3}\right) & =1 \\
V\left(S_{2} \geq S_{1}\right) & =\frac{0.338-0.558}{(0.3207-0.558)-(0.570-0.338)} \\
& =0.469 \\
V\left(S_{2} \geq S_{3}\right) & =1, \\
V\left(S_{3} \geq S_{1}\right) & =0 \\
V\left(S_{3} \geq S_{2}\right) & =0 .
\end{aligned}
$$


TABLE 3: Numerical fuzzy evaluation of criteria.

\begin{tabular}{lccc}
\hline & $C_{1}$ & $C_{2}$ & $C_{3}$ \\
\hline$C_{1}$ & $((1,1,1),(1,1,1))$ & $((0.5,0.75,1),(0.75,1,1))$ & $((0.75,1,1),(0.5,0.75,1))$ \\
$C_{2}$ & $((1,1 / 0.75,1 / 0.5),(0.75,1,1))$ & $((1,1,1),(1,1,1))$ & $((0.75,1,1),(0.75,1,1))$ \\
$C_{3}$ & $((1,1,1 / 0.75),(0.5,0.75,1))$ & $((1,1,1 / 0.75),(0.75,1,1))$ & $((1,1,1),(1,1,1))$ \\
\hline
\end{tabular}

TABLE 4: Regular fuzzy evaluation of criteria.

\begin{tabular}{cccc}
\hline & $C_{1}$ & $C_{2}$ & $C_{3}$ \\
\hline$C_{1}$ & $(1,1,1)$ & $(0.48,0.72,0.96)$ & $(0.65,0.87,0.87)$ \\
$C_{2}$ & $(0.96,1.27,1.91)$ & $(1,1,1)$ & $(0.72,0.96,0.96)$ \\
$C_{3}$ & $(0.87,0.87,1.15)$ & $(0.96,0.96,1.27)$ & $(1,1,1)$ \\
\hline
\end{tabular}

TABLE 5: Comparison matrix with triangular fuzzy number.

\begin{tabular}{lccc}
\hline & $C_{1}$ & $C_{2}$ & $C_{3}$ \\
\hline$C_{1}$ & $(1,1,1)$ & $(1,2,3)$ & $(4,5,6)$ \\
$C_{2}$ & $(1 / 3,1 / 2,1)$ & $(1,1,1)$ & $(2,3,4)$ \\
$C_{3}$ & $(1 / 6,1 / 5,1 / 4)$ & $(1 / 4,1 / 3,1 / 2)$ & $(1,1,1)$ \\
\hline
\end{tabular}

TABLE 6: Comparison matrix with triangular fuzzy number.

\begin{tabular}{cccc}
\hline & $C_{1}$ & $C_{2}$ & $C_{3}$ \\
\hline$C_{1}$ & 1 & 2 & 5 \\
$C_{2}$ & 0.56 & 1 & 3 \\
$C_{3}$ & 0.2 & 0.35 & 1 \\
\hline
\end{tabular}

Finally, by using formula (17), we obtain

$$
\begin{aligned}
d^{\prime}\left(C_{1}\right) & =V\left(S_{1} \geq S_{2}, S_{1} \geq S_{3}\right)=\min (1,1)=1, \\
d^{\prime}\left(C_{2}\right) & =V\left(S_{2} \geq S_{1}, S_{2} \geq S_{3}\right)=\min (0.469,1) \\
& =0.469, \\
d^{\prime}\left(C_{3}\right) & =V\left(S_{3} \geq S_{1}, S_{3} \geq S_{2}\right)=\min (0,0)=0 .
\end{aligned}
$$

Therefore,

$$
W^{\prime}=(1,0.469,0)^{T} \text {. }
$$

Via normalization, we obtain the weight vectors with respect to the decision criteria $C_{1}, C_{2}$, and $C_{3}$ :

$$
W=(0.68,0.32,0)^{T} \text {. }
$$

Then we will use the proposed methodology (GAFAHP) to calculate the optimal priority weight of the comparison matrix (see Table 5).

According to the proposed methodology for the optimal priority weight, after the 50 times of iterations, the changing trend of the fitness of population and the final optimal weight are shown in Figure 10. At last, we obtain the optimal fuzzy weight:

$$
\widetilde{W}=\left(w_{1}, w_{2}, w_{3}\right)^{T}
$$

TABLE 7: Proposed method versus classic FAHP.

\begin{tabular}{lccc}
\hline & $C_{1}$ & $C_{2}$ & $C_{3}$ \\
\hline Classic FAHP [2, 55] & 0.68 & 0.32 & $\mathbf{0 . 0 0}$ \\
The proposed method & 0.59 & 0.29 & 0.12 \\
\hline
\end{tabular}

where $w_{1}=\left(w_{1 l}, w_{1 m}, w_{1 u}\right)=(0.01,0.64,0.69), w_{2}=\left(w_{2 l}\right.$, $\left.w_{2 m}, w_{2 u}\right)=(0.06,0.25,0.35)$, and $w_{3}=\left(w_{3 l}, w_{3 m}, w_{3 u}\right)=$ $(0.03,0.11,0.14)$.

Then, the centroid method is used to convert the optimal fuzzy weight to crisp weight:

$$
W^{\prime}=\left(w_{1}, w_{2}, w_{3}\right)^{T}=(0.45,0.22,0.09)^{T} .
$$

Via normalization, the final priority weight is

$$
W=\left(w_{1}, w_{2}, w_{3}\right)^{T}=(0.59,0.29,0.12)^{T} .
$$

From Table 7, the conclusion can be made that our proposed method is a more efficient method to obtain the priority weight. The reason that classic FAHP is not applicable is that the value of fuzzy synthetic extent has no intersection sometimes, which can be shown in Figure 9, and $S_{2}$ and $S_{3}$ have no intersection. Hence, zero is assigned to the weight of criteria $C_{3}$, which implies that $C_{3}$ is of no use at all. It is extremely unreasonable. Our proposed method can overcome the shortcoming and can get the optimal priority weight all the way.

\section{An Application of Supplier Selection}

Decision-making is widely used in supplier management and selection. In this section, a numerical example originated from [2] is presented to illustrate the procedure of the proposed model.

Owing to the large number of factors affecting the supplier selection decision, an orderly sequence of steps should be required to tackle it. The problem taken here has four levels of hierarchy, and the different decision criterion, attributes, and the decision alternatives will be further discussed. The main objective here is the selection of best global supplier for a manufacturing firm. Application of common criteria to all suppliers makes objective comparisons possible. The criteria which are considered here in selection of the global supplier are as follows:
(a) $\left(C_{1}\right)$ Overall cost of the product.
(b) $\left(C_{2}\right)$ Quality of the product.
(c) $\left(C_{3}\right)$ Service performance of supplier.
(d) $\left(C_{4}\right)$ Supplier profile.
(e) $\left(C_{5}\right)$ Risk factor. 

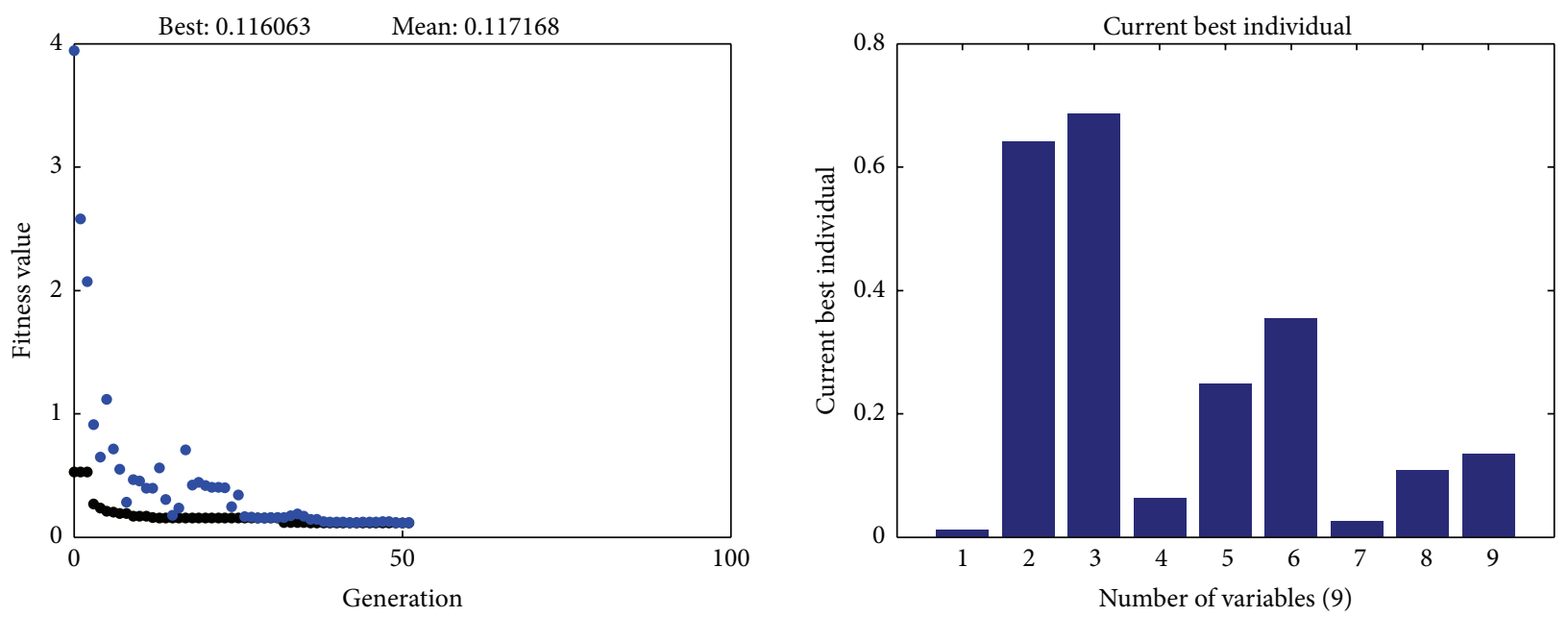

- Best fitness

- Mean fitness
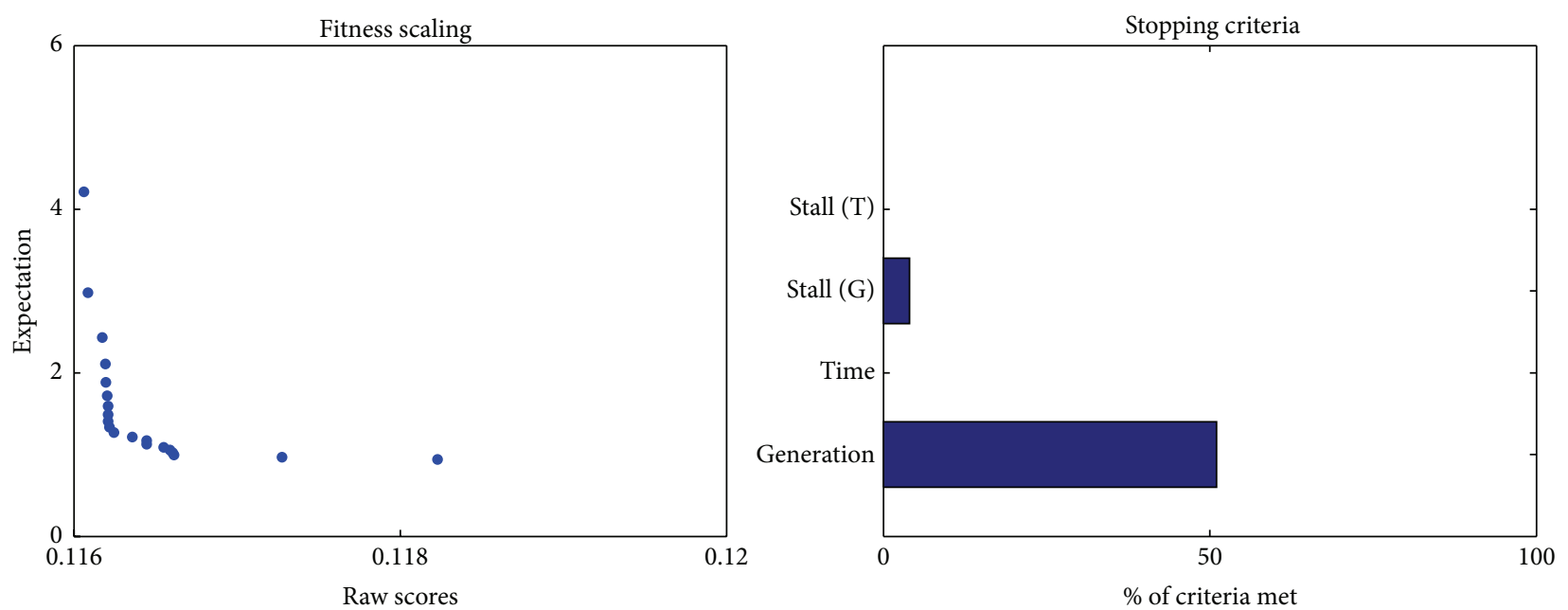

Figure 10: Optimal fuzzy priority weight (upper right) with Genetic Algorithm. Parameters of GA are as follows: population size: 20; scaling function: rank; selection function: stochastic uniform; elite count: 2; crossover fraction: 0.8; mutation function: constraint dependent; crossover function: scattered; migration-direction: forward; migration-fraction: 0.2 ; migration-interval: 20; constraint parameter-initial penalty: 10; constraint parameter-penalty factor: 100; hybrid function: none; stopping criteria: 100 , Inf, $-\operatorname{Inf}, 50, \operatorname{Inf}, 1 e^{-6}, 1 e^{-6}$.

The hierarchy model of supplier selection can be constructed as shown in Figure 11.

As can be seen from Figure 11, the overall cost of the product $\left(C_{1}\right)$ has three factors (attributes): product price $\left(A_{1}\right)$, freight cost $\left(A_{2}\right)$, and tariff and custom duties $\left(A_{3}\right)$. The quality of the product $\left(C_{2}\right)$ has four factors: rejection rate of the product $\left(A_{4}\right)$, increased lead time $\left(A_{5}\right)$, quality assessment $\left(A_{6}\right)$, and remedy for quality problems $\left(A_{7}\right)$. The service performance $\left(C_{3}\right)$ has four attributes: delivery schedule $\left(A_{8}\right)$, technological and R\&D support $\left(A_{9}\right)$, response to changes $\left(A_{10}\right)$, and ease of communication $\left(A_{11}\right)$. The suppliers profile $\left(C_{4}\right)$ has four attributes: financial status $\left(A_{12}\right)$, customer base $\left(A_{13}\right)$, performance history $\left(A_{14}\right)$, and production facility and capacity $\left(A_{15}\right)$. The risk factor $\left(C_{5}\right)$ has four attributes: geographical location $\left(A_{16}\right)$, political stability $\left(A_{17}\right)$, economy $\left(A_{18}\right)$, and terrorism $\left(A_{19}\right)$. Refer to [2] for more detailed information about the attributes mentioned above.

After the construction of the decision hierarchy of supplier selection, the fuzzy evaluation matrix of the criterion is constructed by the pairwise comparison of the different criterion relevant to the overall objective using $Z$-numbers.

The fuzzy evaluation of criteria with respect to the overall objective can be listed in Table 8 . The final weights of each criteria can be determined by the proposed method. The detailed calculation process is given in Sections 3 and 4 . The results are listed in right side of Table 8.

In a similar way, the fuzzy evaluation of the attributes with respect to criteria $C_{1}$ to $C_{6}$ can be given by domain experts and the corresponding results based on the proposed method are listed in Tables 9-13, respectively. 
TABLE 8: Fuzzy evaluation of criteria with respect to the overall objective.

\begin{tabular}{|c|c|c|c|c|c|c|}
\hline$O$ & $C_{1}$ & $\mathrm{C}_{2}$ & $\mathrm{C}_{3}$ & $\mathrm{C}_{4}$ & $C_{5}$ & $\overline{W_{o}}$ \\
\hline$C_{1}$ & {$[(1,1,1),(1,1,1)]$} & {$[(3 / 2,2,5 / 2), \mathrm{VH}]$} & {$[(3 / 2,2,5 / 2), \mathrm{VH}]$} & {$[(5 / 2,3,7 / 2), H]$} & {$[(5 / 2,3,7 / 2), \mathrm{VH}]$} & 0.49 \\
\hline $\mathrm{C}_{2}$ & {$[(2 / 5,1 / 2,2 / 3), \mathrm{VH}]$} & {$[(1,1,1),(1,1,1)]$} & {$[(3 / 2,2,5 / 2), M]$} & {$[(5 / 2,3,7 / 2), \mathrm{VH}]$} & {$[(5 / 2,3,7 / 2), \mathrm{VH}]$} & 0.19 \\
\hline$C_{3}$ & {$[(2 / 5,1 / 2,2 / 3), \mathrm{VH}]$} & {$[(2 / 5,1 / 2,2 / 3), M]$} & {$[(1,1,1),(1,1,1)]$} & {$[(3 / 2,2,5 / 2), \mathrm{VH}]$} & {$[(3 / 2,2,5 / 2), \mathrm{VH}]$} & 0.15 \\
\hline$C_{4}$ & {$[(2 / 7,1 / 3,2 / 5), \mathrm{H}]$} & {$[(2 / 7,1 / 3,2 / 5), \mathrm{VH}]$} & {$[(2 / 5,1 / 2,2 / 3), \mathrm{VH}]$} & {$[(1,1,1),(1,1,1)]$} & {$[(3 / 2,2,5 / 2), M]$} & 0.11 \\
\hline$C_{5}$ & {$[(2 / 7,1 / 3,2 / 5), \mathrm{VH}]$} & {$[(2 / 7,1 / 3,2 / 5), \mathrm{VH}]$} & {$[(2 / 5,1 / 2,2 / 3), \mathrm{VH}]$} & {$[(2 / 5,1 / 2,2 / 3), \mathrm{M}]$} & {$[(1,1,1),(1,1,1)]$} & 0.05 \\
\hline
\end{tabular}

TABLe 9: Fuzzy evaluation of the attributes with respect to criterion $C_{1}$.

\begin{tabular}{lcccc}
\hline$C_{1}$ & $A_{1}$ & $A_{2}$ & $A_{3}$ & $W_{C_{1}}$ \\
\hline$A_{1}$ & {$[(1,1,1),(1,1,1)]$} & {$[(3 / 2,2,5 / 2), \mathrm{VH}]$} & {$[(3 / 2,2,5 / 2), \mathrm{H}]$} & 0.47 \\
$A_{2}$ & {$[(2 / 5,1 / 2,2 / 3), \mathrm{VH}]$} & {$[(1,1,1),(1,1,1)]$} & {$[(3 / 2,2,5 / 2), \mathrm{VH}]$} & 0.30 \\
$A_{3}$ & {$[(2 / 5,1 / 2,2 / 3), \mathrm{H}]$} & {$[(2 / 5,1 / 2,2 / 3), \mathrm{VH}]$} & {$[(1,1,1),(1,1,1)]$} & 0.24 \\
\hline
\end{tabular}

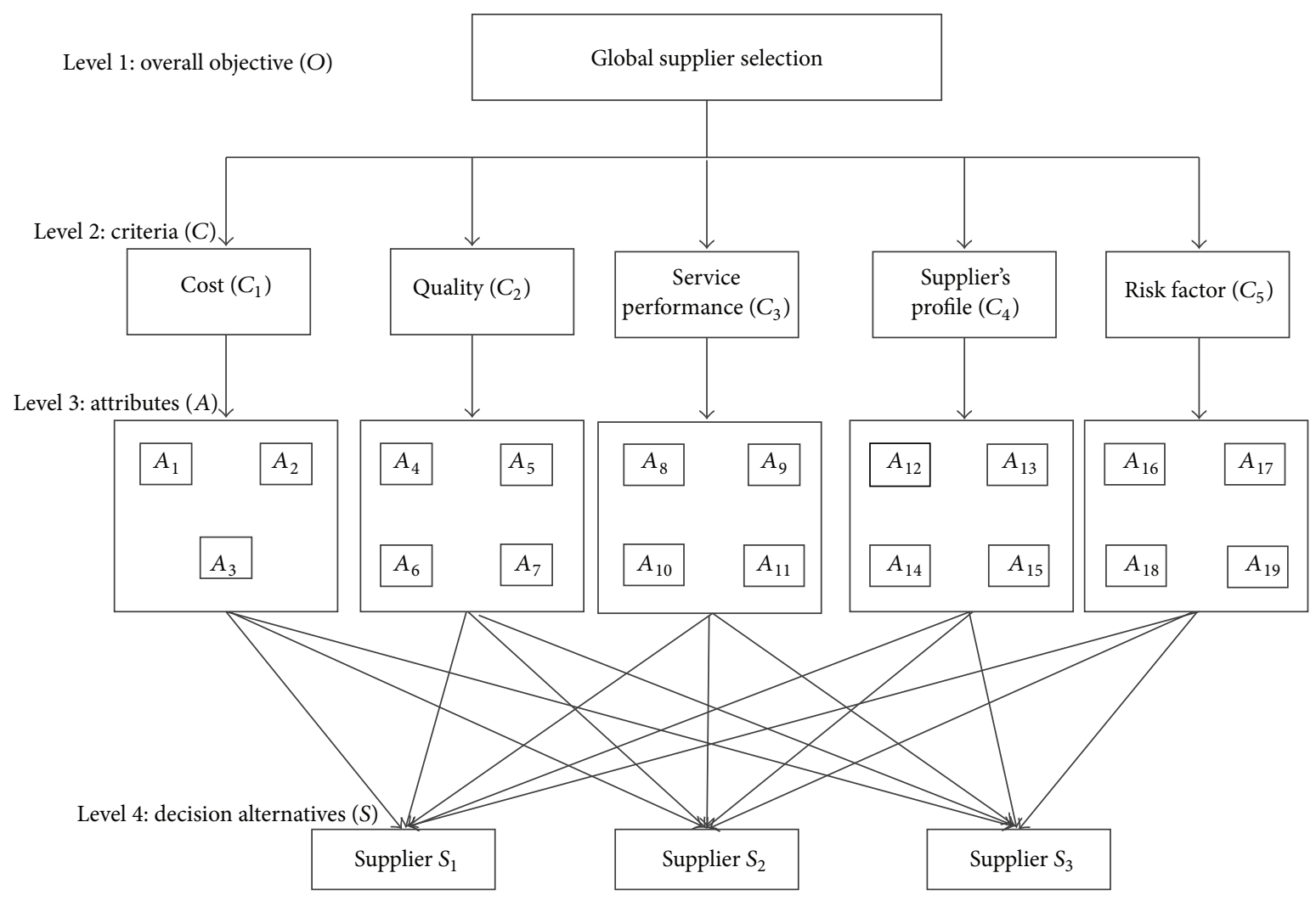

FIGURE 11: Hierarchy for the global supplier selection.

For the criterion $C_{1}$, the summary combination of priority weights can be listed in Table 14 . Also, the other summary combinations of priority weights of $C_{2}$ to $C_{5}$ are shown in Tables 15-18.

The Fuzzy evaluation of criterion with respect to the overall objective can be shown in Table 19. As can be seen from Table 19 and Figure 12, the best supplier is $S_{1}$.

\section{Conclusions and Future Work}

The supplier selection is a significant issue of multicriteria decision-making (MCDM), which has been researched for decades. However, the reliability of the knowledge from experts/commanders is not efficiently taken into consideration. After the notion of $Z$-number was introduced by Zadeh in 2011, some attention has been paid to this concept. $Z$-number has more capability to describe uncertain information with both restraint and reliability. In this paper, a methodology for supplier selection using $Z$-numbers is proposed, which includes two parts: one solves the issue of how to convert $Z$-number to classic fuzzy number; the other solves the problem of how to get the optimal priority weight for supplier selection with GA, which is more efficient comparing with the classic FAHP. At last, a designed example 
TABLE 10: Fuzzy evaluation of the attributes with respect to criterion $C_{2}$.

\begin{tabular}{ccccc}
\hline$C_{2}$ & $A_{4}$ & $A_{5}$ & $A_{6}$ & $W_{7}$ \\
\hline$A_{4}$ & {$[(1,1,1),(1,1,1)]$} & {$[(3 / 2,2,5 / 2), \mathrm{VH}]$} & {$[(2 / 3,1,3 / 2), \mathrm{M}]$} & {$[(5 / 2,3,7 / 2), \mathrm{VH}]$} \\
$A_{5}$ & {$[(2 / 5,1 / 2,2 / 3), \mathrm{VH}]$} & {$[(1,1,1),(1,1,1)]$} & {$[(2 / 3,1,3 / 2), \mathrm{VH}]$} & 0.32 \\
$A_{6}$ & {$[(2 / 3,1,3 / 2), \mathrm{M}]$} & {$[(2 / 3,1,3 / 2), \mathrm{VH}]$} & {$[(1,1,1),(1,1,1)]$} & {$[(3 / 2,2,5 / 2), \mathrm{H}]$} \\
$A_{7}$ & {$[(2 / 7,1 / 3,2 / 5), \mathrm{VH}]$} & {$[(2 / 5,1 / 2,2 / 3), \mathrm{H}]$} & {$[(2 / 5,1 / 2,2 / 3), \mathrm{VH}]$} & 0.23 \\
\hline
\end{tabular}

TABLE 11: Fuzzy evaluation of the attributes with respect to criterion $C_{3}$.

\begin{tabular}{lcccc}
\hline$C_{3}$ & $A_{8}$ & $A_{9}$ & $A_{10}$ & $A_{11}$ \\
\hline$A_{8}$ & {$[(1,1,1),(1,1,1)]$} & {$[(3 / 2,2,5 / 2), \mathrm{M}]$} & {$[(5 / 2,3,7 / 2), \mathrm{VH}]$} & {$[(7 / 2,4,9 / 2), \mathrm{H}]$} \\
$A_{9}$ & {$[(2 / 5,1 / 2,2 / 3), \mathrm{M}]$} & {$[(1,1,1),(1,1,1)]$} & {$[(5 / 2,3,7 / 2), \mathrm{H}]$} & 0.43 \\
$A_{10}$ & {$[(2 / 7,1 / 3,2 / 5), \mathrm{VH}]$} & {$[(2 / 7,1 / 3,2 / 5), \mathrm{H}]$} & {$[(1,1,1),(1,1,1)]$} & {$[(5 / 2,3,7 / 2), \mathrm{VH}]$} \\
$A_{11}$ & {$[(2 / 9,1 / 4,2 / 7), \mathrm{H}]$} & {$[(2 / 7,1 / 3,2 / 5), \mathrm{VH}]$} & {$[(2 / 5,1 / 2,2 / 3), \mathrm{VH}]$} & 0.28 \\
\hline
\end{tabular}

TABLE 12: Fuzzy evaluation of the attributes with respect to criterion $C_{4}$.

\begin{tabular}{|c|c|c|c|c|c|}
\hline $\mathrm{C}_{4}$ & $A_{12}$ & $A_{13}$ & $A_{14}$ & $A_{15}$ & $W_{C_{4}}$ \\
\hline$A_{12}$ & {$[(1,1,1),(1,1,1)]$} & {$[(3 / 2,2,5 / 2), \mathrm{VH}]$} & {$[(3 / 2,2,5 / 2), \mathrm{VH}]$} & {$[(7 / 2,4,9 / 2), \mathrm{H}]$} & 0.44 \\
\hline$A_{13}$ & {$[(2 / 5,1 / 2,2 / 3), \mathrm{VH}]$} & {$[(1,1,1),(1,1,1)]$} & {$[(2 / 5,1 / 2,2 / 3), \mathrm{VH}]$} & {$[(3 / 2,2,5 / 2), H]$} & 0.21 \\
\hline$A_{14}$ & {$[(2 / 5,1 / 2,2 / 3), \mathrm{VH}]$} & {$[(2 / 7,1 / 3,2 / 5), \mathrm{VH}]$} & {$[(1,1,1),(1,1,1)]$} & {$[(3 / 2,2,5 / 2), \mathrm{VH}]$} & 0.21 \\
\hline$A_{15}$ & {$[(2 / 9,1 / 4,2 / 7), \mathrm{H}]$} & {$[(2 / 5,1 / 2,2 / 3), \mathrm{H}]$} & {$[(2 / 5,1 / 2,2 / 3), \mathrm{VH}]$} & {$[(1,1,1),(1,1,1)]$} & 0.13 \\
\hline
\end{tabular}

TABLE 13: Fuzzy evaluation of the attributes with respect to criterion $C_{5}$.

\begin{tabular}{lcccr}
\hline$C_{5}$ & $A_{16}$ & $A_{17}$ & $A_{18}$ & $A_{19}$ \\
\hline$A_{16}$ & {$[(1,1,1),(1,1,1)]$} & {$[(2 / 3,1,3 / 2), \mathrm{H}]$} & {$[(2 / 3,1,3 / 2), \mathrm{VH}]$} & {$[(2 / 3,1,3 / 2), \mathrm{VH}]$} \\
$A_{17}$ & {$[(2 / 3,1,3 / 2), \mathrm{H}]$} & {$[(1,1,1),(1,1,1)]$} & {$[(3 / 2,2,5 / 2), \mathrm{VH}]$} & 0.28 \\
$A_{18}$ & {$[(2 / 3,1,3 / 2), \mathrm{VH}]$} & {$[(2 / 5,1 / 2,2 / 3), \mathrm{VH}]$} & {$[(1,1,1),(1,1,1)]$} & {$[(3 / 2,2,5 / 2), \mathrm{M}]$} \\
$A_{19}$ & {$[(2 / 3,1,3 / 2), \mathrm{VH}]$} & {$[(2 / 5,1 / 2,2 / 3), \mathrm{M}]$} & {$[(2 / 5,1 / 2,2 / 3), \mathrm{VH}]$} & 0.31 \\
\hline
\end{tabular}

TABLE 14: Summary combination of priority weights: attributes of criterion $C_{1}$.

\begin{tabular}{lcccc}
\hline Weight & $A_{1}$ & $A_{2}$ & $A_{3}$ & Priority weight \\
& 0.47 & 0.30 & 0.24 & \\
\hline Alternatives & & & & \\
$S_{1}$ & 0.71 & 0.44 & 0.69 & 0.63 \\
$S_{2}$ & 0.13 & 0.36 & 0.08 & 0.19 \\
$S_{3}$ & 0.16 & 0.20 & 0.23 & 0.19 \\
\hline
\end{tabular}

TABLE 15: Summary combination of priority weights: attributes of criterion $\mathrm{C}_{2}$.

\begin{tabular}{lccccc}
\hline Weight & $A_{4}$ & $A_{5}$ & $A_{6}$ & $A_{7}$ & Priority weight \\
& 0.32 & 0.23 & 0.32 & 0.14 & \\
\hline Alternatives & & & & & \\
$S_{1}$ & 0.51 & 0.51 & 0.69 & 0.87 & 0.62 \\
$S_{2}$ & 0.23 & 0.23 & 0.08 & 0.00 & 0.15 \\
$S_{3}$ & 0.26 & 0.26 & 0.23 & 0.13 & 0.23 \\
\hline
\end{tabular}

TABLE 16: Summary combination of priority weights: attributes of criterion $\mathrm{C}_{3}$.

\begin{tabular}{lccccc}
\hline Weight & $A_{8}$ & $A_{9}$ & $A_{10}$ & $A_{11}$ & Priority weight \\
& 0.43 & 0.28 & 0.17 & 0.11 & \\
\hline Alternatives & & & & & \\
$S_{1}$ & 0.27 & 0.69 & 0.05 & 0.49 & 0.38 \\
$S_{2}$ & 0.18 & 0.08 & 0.64 & 0.32 & 0.25 \\
$S_{3}$ & 0.55 & 0.23 & 0.31 & 0.19 & 0.38 \\
\hline
\end{tabular}

TABLE 17: Summary combination of priority weights: attributes of criterion $\mathrm{C}_{4}$.

\begin{tabular}{lccccc}
\hline Weight & $A_{12}$ & $A_{13}$ & $A_{14}$ & $A_{15}$ & Priority weight \\
& 0.44 & 0.21 & 0.21 & 0.13 & \\
\hline Alternatives & & & & & \\
$S_{1}$ & 0.83 & 0.45 & 0.69 & 0.33 & 0.66 \\
$S_{2}$ & 0.17 & 0.45 & 0.08 & 0.33 & 0.51 \\
$S_{3}$ & 0.00 & 0.10 & 0.23 & 0.34 & 0.18 \\
\hline
\end{tabular}


TABLE 18: Summary combination of priority weights: attributes of criterion $\mathrm{C}_{5}$.

\begin{tabular}{lccccc}
\hline Weight & $A_{16}$ & $A_{17}$ & $A_{18}$ & $A_{19}$ & Priority weight \\
& 0.28 & 0.31 & 0.24 & 0.17 & \\
\hline Alternatives & & & & & \\
$S_{1}$ & 0.72 & 0.49 & 0.83 & 0.27 & 0.60 \\
$S_{2}$ & 0.00 & 0.32 & 0.17 & 0.18 & 0.17 \\
$S_{3}$ & 0.28 & 0.19 & 0.00 & 0.55 & 0.23 \\
\hline
\end{tabular}

TABLE 19: Summary combination of priority weights: main criterion of the overall objective.

\begin{tabular}{lcccccc}
\hline Weight & $C_{1}$ & $C_{2}$ & $C_{3}$ & $C_{4}$ & $C_{5}$ & Priority weight \\
& 0.49 & 0.19 & 0.15 & 0.11 & 0.05 & \\
\hline Alternatives & & & & & & \\
$S_{1}$ & 0.63 & 0.62 & 0.38 & 0.66 & 0.60 & 0.59 \\
$S_{2}$ & 0.19 & 0.15 & 0.25 & 0.51 & 0.17 & 0.22 \\
$S_{3}$ & 0.19 & 0.23 & 0.38 & 0.18 & 0.23 & 0.23 \\
\hline
\end{tabular}

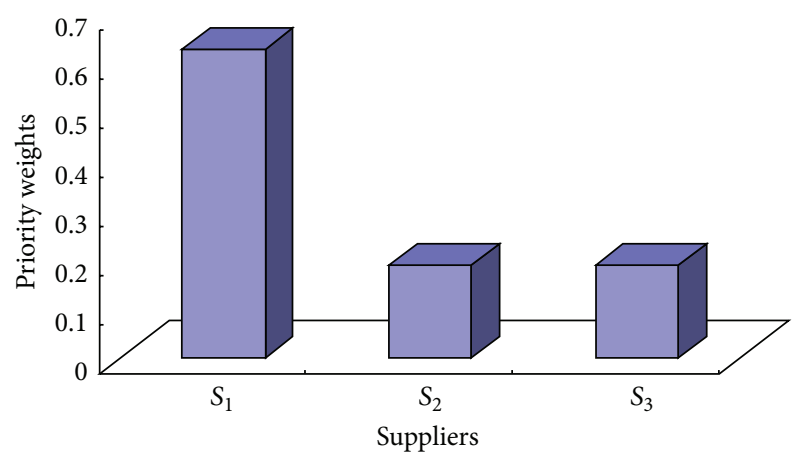

FIGURE 12: Final priority weights of each supplier.

for supplier selection is used to illustrate the proposed methodology.

$Z$-number is a new notion which has a flexible presentation of uncertain information to simulate the knowledge or behavior of human being. The comparison of different $Z$ numbers is an important and open issue, which is also the fundamental issue to expand the application of $Z$-number. This is the future work we will concern.

\section{Conflict of Interests}

The authors declare that there is no conflict of interests regarding the publication of this paper.

\section{Authors' Contribution}

Bingyi Kang and Yong Hu contributed equally to this work.

\section{Acknowledgments}

The work is partially supported by National High Technology Research and Development Program of China (863 Program) (Grant no. 2013AA013801), National Natural Science Foundation of China (Grant nos. 61174022, 61573290, and 61503237), and China State Key Laboratory of Virtual Reality Technology and Systems, Beihang University (Grant no. BUAA-VR-14KF-02).

\section{References}

[1] F. T. S. Chan, N. Kumar, and K. L. Choy, "Decision-making approach for the distribution centre location problem in a supply chain network using the fuzzy-based hierarchical concept," Proceedings of the Institution of Mechanical Engineers, Part B: Journal of Engineering Manufacture, vol. 221, no. 4, pp. 725-739, 2007.

[2] F. T. S. Chan and N. Kumar, "Global supplier development considering risk factors using fuzzy extended AHP-based approach," Omega, vol. 35, no. 4, pp. 417-431, 2007.

[3] E. Timmerman, "An approach to vendor performance evaluation," IEEE Engineering Management Review, vol. 15, no. 3, pp. 14-20, 1987.

[4] W. Soukup, "Supplier selection strategies," Journal of Purchasing and Materials Management, vol. 23, pp. 7-12, 1987.

[5] D. J. Rapport, "An optimization model of food selection," The American Naturalist, vol. 105, no. 946, pp. 575-587, 1971.

[6] S. H. Ghodsypour and C. O'Brien, "The total cost of logistics in supplier selection, under conditions of multiple sourcing, multiple criteria and capacity constraint," International Journal of Production Economics, vol. 73, no. 1, pp. 15-27, 2001.

[7] A. Charnes, W. W. Cooper, J. K. Devoe, D. B. Learner, and W. Reinecke, "A goal programming model for media planning," Management Science, vol. 14, no. 8, pp. B-423-B-430, 1968.

[8] K. Choy and W. Lee, "On the development of a case-based supplier management tool for multi-national manufacturers," Measuring Business Excellence, vol. 6, no. 1, pp. 15-22, 2002.

[9] J. Liu, F.-Y. Ding, and V. Lall, "Using data envelopment analysis to compare suppliers for supplier selection and performance improvement," Supply Chain Management, vol. 5, no. 3, pp. 143$150,2000$.

[10] W. Jiang, Y. Luo, X. Qin, and J. Zhan, "An improved method to rank generalized fuzzy numbers with different left heights and right heights," Journal of Intelligent \& Fuzzy Systems, vol. 28, no. 5, pp. 2343-2355, 2015.

[11] D. W. Cho and Y. H. Lee, "The value of information sharing in a supply chain with a seasonal demand process," Computers of Industrial Engineering, vol. 65, no. 1, pp. 97-108, 2013.

[12] S. I. Mari, Y. H. Lee, and M. S. Memon, "Sustainable and resilient supply chain network design under disruption risks," Sustainability, vol. 6, no. 10, pp. 6666-6686, 2014.

[13] S. I. Mari, Y. H. Lee, M. S. Memon, Y. S. Park, and M. Kim, "Adaptivity of complex network topologies for designing resilient supply chain networks," The International Journal of Industrial Engineering: Theory, Applications and Practice, vol. 22, no. 1, pp. 102-116, 2015.

[14] S. Sardar and Y. H. Lee, "Analysis of product complexity considering disruption cost in fast fashion supply chain," Mathematical Problems in Engineering, vol. 2015, Article ID 670831, 15 pages, 2015. 
[15] J. H. Moon, Y. H. Lee, and D. W. Cho, "Object-oriented simulation modeling for service supply chain," Journal of the Korea Society for Simulation, vol. 21, no. 1, pp. 55-68, 2012.

[16] F. Hosseinpour and H. Hajihosseini, "Importance of simulation in manufacturing," World Academy of Science, Engineering and Technology, vol. 51, pp. 285-288, 2009.

[17] B. Kang, Y. Deng, R. Sadiq, and S. Mahadevan, "Evidential cognitive maps," Knowledge-Based Systems, vol. 35, pp. 77-86, 2012.

[18] Y. Deng, "Generalized evidence theory," Applied Intelligence, vol. 43, no. 3, pp. 530-543, 2015.

[19] G. Wang, S. H. Huang, and J. P. Dismukes, "Product-driven supply chain selection using integrated multi-criteria decisionmaking methodology," International Journal of Production Economics, vol. 91, no. 1, pp. 1-15, 2004.

[20] S. H. Ghodsypour and C. O’Brien, "A decision support system for supplier selection using an integrated analytic hierarchy process and linear programming," International Journal of Production Economics, vol. 56-57, pp. 199-212, 1998.

[21] A. Amid, S. H. Ghodsypour, and C. O’Brien, "A weighted maxmin model for fuzzy multi-objective supplier selection in a supply chain," International Journal of Production Economics, vol. 131, no. 1, pp. 139-145, 2011.

[22] S. Aydin and C. Kahraman, "Multiattribute supplier selection using fuzzy analytic Hierarchy process," International Journal of Computational Intelligence Systems, vol. 3, no. 5, pp. 553-565, 2010.

[23] T.-Y. Wang and Y.-H. Yang, "A fuzzy model for supplier selection in quantity discount environments," Expert Systems with Applications, vol. 36, no. 10, pp. 12179-12187, 2009.

[24] J. L. Yang, H. N. Chiu, G.-H. Tzeng, and R. H. Yeh, "Vendor selection by integrated fuzzy MCDM techniques with independent and interdependent relationships," Information Sciences, vol. 178, no. 21, pp. 4166-4183, 2008.

[25] M. Sevkli, "An application of the fuzzy ELECTRE method for supplier selection," International Journal of Production Research, vol. 48, no. 12, pp. 3393-3405, 2010.

[26] F. T. S. Chan, N. Kumar, M. K. Tiwari, H. C. W. Lau, and K. L. Choy, "Global supplier selection: a fuzzy-AHP approach," International Journal of Production Research, vol. 46, no. 14, pp. 3825-3857, 2008.

[27] F. T. S. Chan, H. K. Chan, R. W. L. Ip, and H. C. W. Lau, "A decision support system for supplier selection in the airline industry," Proceedings of the Institution of Mechanical Engineers, Part B: Journal of Engineering Manufacture, vol. 221, no. 4, pp. 741-758, 2007.

[28] X. Deng, Y. Hu, Y. Deng, and S. Mahadevan, "Supplier selection using AHP methodology extended by D numbers," Expert Systems with Applications, vol. 41, no. 1, pp. 156-167, 2014.

[29] X. Su, S. Mahadevan, P. Xu, and Y. Deng, "Dependence assessment in Human Reliability Analysis using evidence theory and AHP," Risk Analysis, vol. 35, no. 7, pp. 1296-1316, 2015.

[30] K. Shahgholian, A. Shahraki, Z. Vaezi, and H. Hajihosseini, "A model for supplier selection based on fuzzy multi-criteria group decision making," African Journal of Business Management, vol. 6, pp. 6254-6265, 2012.

[31] Z. Wang, K. W. Li, and J. Xu, "A mathematical programming approach to multi-attribute decision making with intervalvalued intuitionistic fuzzy assessment information," Expert Systems with Applications, vol. 38, no. 10, pp. 12462-12469, 2011.
[32] G. N. Yücenur, Ö. Vayvay, and N. Ç. Demirel, "Supplier selection problem in global supply chains by AHP and ANP approaches under fuzzy environment," The International Journal of Advanced Manufacturing Technology, vol. 56, no. 5-8, pp. 823-833, 2011.

[33] X. Deng, Y. Hu, Y. Deng, and S. Mahadevan, "Environmental impact assessment based on D numbers," Expert Systems with Applications, vol. 41, no. 2, pp. 635-643, 2014.

[34] X. Deng, X. Lu, F. T. S. Chan, R. Sadiq, S. Mahadevan, and Y. Deng, "D-CFPR: D numbers extended consistent fuzzy preference relations," Knowledge-Based Systems, vol. 73, pp. 6168, 2015.

[35] M. S. Memon, Y. H. Lee, and S. I. Mari, "Group multi-criteria supplier selection using combined grey systems theory and uncertainty theory," Expert Systems with Applications, vol. 42, no. 21, pp. 7951-7959, 2015.

[36] N. Xie and J. Xin, "Interval grey numbers based multi-attribute decision making method for supplier selection," Kybernetes, vol. 43, no. 7, pp. 1064-1078, 2014.

[37] L. A. Zadeh, "A note on z-numbers," Information Sciences, vol. 181, no. 14, pp. 2923-2932, 2011.

[38] K.-J. Kim and I. Han, "Maintaining case-based reasoning systems using a genetic algorithms approach," Expert Systems with Applications, vol. 21, no. 3, pp. 139-145, 2001.

[39] C.-S. Park and I. Han, "A case-based reasoning with the feature weights derived by analytic hierarchy process for bankruptcy prediction," Expert Systems with Applications, vol. 23, no. 3, pp. 255-264, 2002.

[40] C. Elmas, O. Ustun, and H. H. Sayan, "A neuro-fuzzy controller for speed control of a permanent magnet synchronous motor drive," Expert Systems with Applications, vol. 34, no. 1, pp. 657664, 2008.

[41] S. Soyguder, M. Karakose, and H. Alli, "Design and simulation of self-tuning PID-type fuzzy adaptive control for an expert HVAC system," Expert Systems with Applications, vol. 36, no. 3, pp. 4566-4573, 2009.

[42] Y. Deng, Y. Liu, and D. Zhou, "An improved genetic algorithm with initial population strategy for symmetric TSP," Mathematical Problems in Engineering, vol. 2015, Article ID 212794, 6 pages, 2015.

[43] C. Fu and S.-L. Yang, "The group consensus based evidential reasoning approach for multiple attributive group decision analysis," European Journal of Operational Research, vol. 206, no. 3, pp. 601-608, 2010.

[44] C. Fu and S. L. Yang, "An attribute weight based feedback model for multiple attributive group decision analysis problems with group consensus requirements in evidential reasoning context," European Journal of Operational Research, vol. 212, no. 1, pp. 179-189, 2011.

[45] S. Tsai, M. F. Chien, Y. Xue et al., "Using the fuzzy dematel to determine environmental performance: a case of printed circuit board industry in Taiwan," PLoS ONE, vol. 10, no. 6, Article ID e0129153, 2015.

[46] S. B. Tsai, Y. Z. Xue, P. Y. Huang et al., "Establishing a criteria system for green production," Proceedings of the Institution of Mechanical Engineers, Part B: Journal of Engineering Manufacture, vol. 229, no. 8, pp. 1395-1406, 2014.

[47] L. A. Zadeh, "Fuzzy sets," Information and Control, vol. 8, pp. 338-353, 1965.

[48] Y. Deng, W. Jiang, and R. Sadiq, "Modeling contaminant intrusion in water distribution networks: a new similarity-based 
DST method," Expert Systems with Applications, vol. 38, no. 1, pp. 571-578, 2011.

[49] Y. Deng, R. Sadiq, W. Jiang, and S. Tesfamariam, "Risk analysis in a linguistic environment: a fuzzy evidential reasoning-based approach," Expert Systems with Applications, vol. 38, no. 12, pp. 15438-15446, 2011.

[50] Y. Deng and F. T. S. Chan, "A new fuzzy dempster MCDM method and its application in supplier selection," Expert Systems with Applications, vol. 38, no. 8, pp. 9854-9861, 2011.

[51] Y. Deng, F. T. S. Chan, Y. Wu, and D. Wang, "A new linguistic MCDM method based on multiple-criterion data fusion," Expert Systems with Applications, vol. 38, no. 6, pp. 6985-6993, 2011.

[52] W. Jiang, Y. Yang, Y. Luo, and X. Qin, "Determining basic probability assignment based on the improved similarity measures of generalized fuzzy numbers," International Journal of Computers Communications \& Control, vol. 10, no. 3, pp. 333-347, 2015.

[53] Y. Deng, "A threat assessment model under uncertain environment," Mathematical Problems in Engineering, vol. 2015, Article ID 878024, 12 pages, 2015.

[54] T. L. Saaty, The Analytic Hierarchy Process: Planning, Priority Setting, Resources Allocation, McGraw-Hill, New York, NY, USA, 1980.

[55] D.-Y. Chang, "Applications of the extent analysis method on fuzzy AHP," European Journal of Operational Research, vol. 95, no. 3, pp. 649-655, 1996.

[56] D.-Y. Chang, "Applications of the extent analysis method on fuzzy AHP," European Journal of Operational Research, vol. 95, no. 3, pp. 649-655, 1996.

[57] B. Kang, D. Wei, Y. Li, and Y. Deng, "A method of converting Znumber to classical fuzzy number," Journal of Information and Computational Science, vol. 9, no. 3, pp. 703-709, 2012.

[58] G. Rudolph, "Convergence analysis of canonical genetic algorithms," IEEE Transactions on Neural Networks, vol. 5, no. 1, pp. 96-101, 1994.

[59] J.-M. Renders and S. P. Flasse, "Hybrid methods using genetic algorithms for global optimization," IEEE Transactions on Systems, Man, and Cybernetics, Part B: Cybernetics, vol. 26, no. 2, pp. 243-258, 1996.

[60] W. Zhong, J. Liu, M. Xue, and L. Jiao, "A multiagent genetic algorithm for global numerical optimization," IEEE Transactions on Systems, Man, and Cybernetics, Part B: Cybernetics, vol. 34, no. 2, pp. 1128-1141, 2004.

[61] C. K. Kwong and H. Bai, "Determining the importance weights for the customer requirements in qfd using a fuzzy ahp with an extent analysis approach," IIE Transactions, vol. 35, no. 7, pp. 619-626, 2003. 


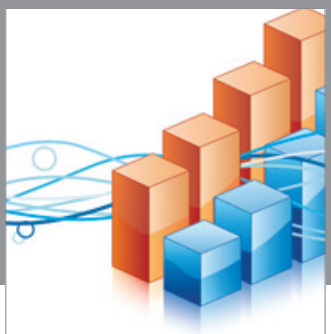

Advances in

Operations Research

vatem alat4

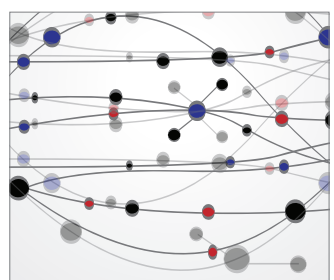

\section{The Scientific} World Journal
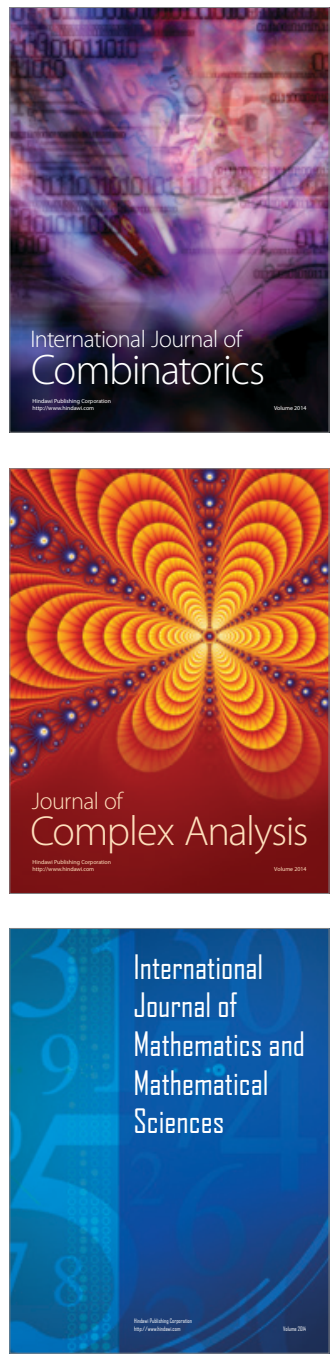
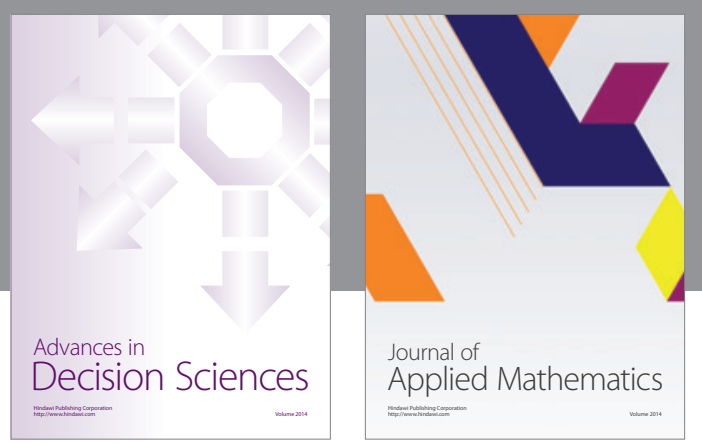

Algebra

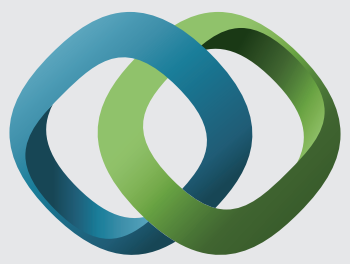

\section{Hindawi}

Submit your manuscripts at

http://www.hindawi.com
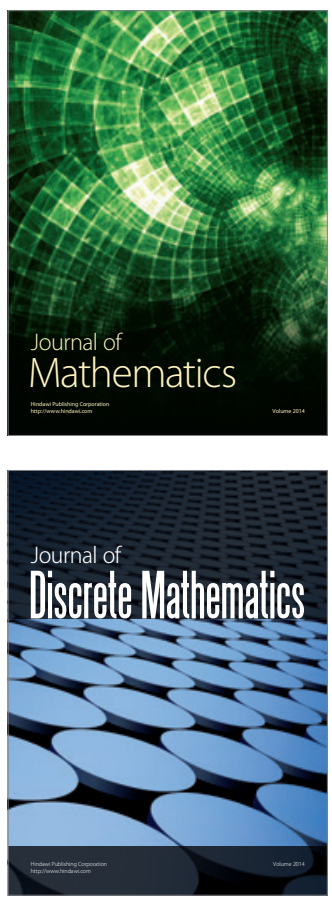

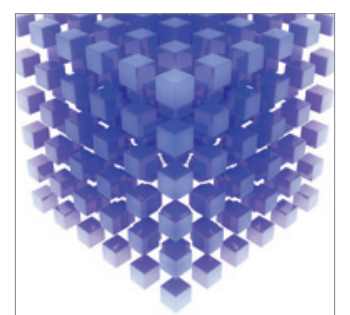

Mathematical Problems in Engineering
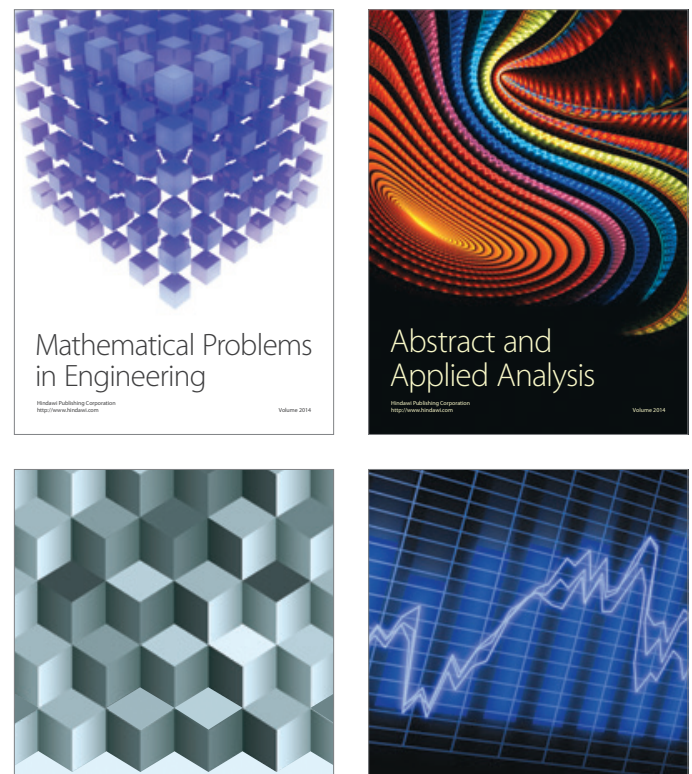

Journal of

Function Spaces

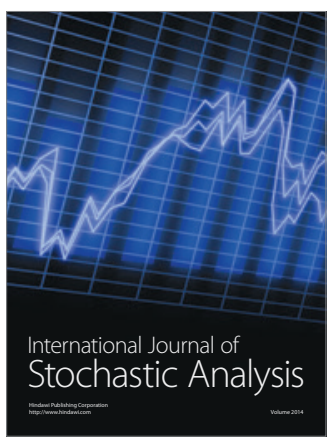

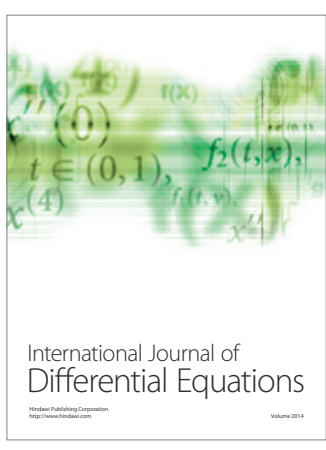
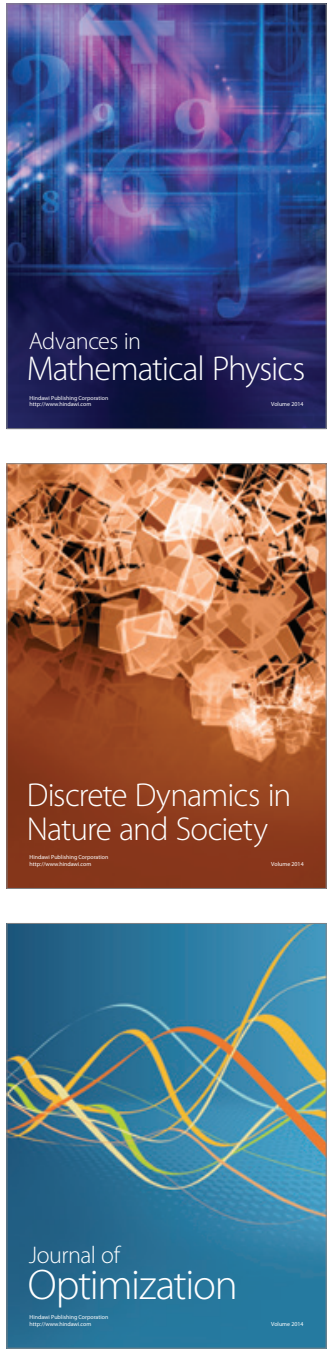